"em port'final" — 2021/5/3 - 12:15 — page 1 — \#1

\title{
Global Risk in Long-Term Sovereign Debt
}

\author{
Nicola Borri \\ LUISS University \\ Kirill Shakhnov \\ University of Surrey
}

This paper focuses on emerging market government bonds issued in local currency with different maturities. Foreign investors face interest rate, currency, and credit risks. We consider the entire term structure of carry trade returns and find that, while the default premium does not contribute to carry trade strategies, the contribution of interest rate risk, captured by the term premium, is large and increases with maturity. We introduce default risk in an otherwise standard affine model; we show that the volatility of the permanent component of the SDFs must be different across emerging markets in order to match these stylized facts. (JEL F31, F34, G15)

Received XXXX XX, XXXX; editorial decision XXXX XX, XXXX by Editor XXXXXXXXXXXX.

We are especially thankful to Pierpaolo Benigno, Wenxin Du, Matteo Maggiori, Marco Pagano, Paolo Porchia, Nick Roussanov (the editor), Jesse Schreger, Aleh Tsyvinski; two anonymous referees; and seminar participants at LUISS University, University of York Asset Pricing Workshop, Bank of Italy, Fulcrum Asset Management, and the Econometric Society World Congress (2020). Send correspondence to Nicola Borri, nborri@luiss.it.

Published by Oxford University Press on behalf of The Society for Financial Studies 2014 doi:10.1093/rapstu/Sample

Advance Access publication September 21, 2014 
For advanced economies, Lustig et al. (2019) considers an investment horizon of 1 month and finds that currency carry trade strategies implemented with Treasury bonds are different from those that use Treasury bills. While the latter are profitable, the former produce excess returns not significantly different from zero because currency premiums are offset by local currency term premiums. This finding highlights the deep connection between currency and bond risk premiums in international developed markets.

In this paper, we also consider currency carry trade strategies implemented with Treasury bills and Treasury bonds, but for emerging markets with sizeable default risk. In contrast to previous results for advanced economies, we find negative and significant carry trade returns which further decrease with the maturity of the bonds. This means that, as bond maturity increases, low interest rate currency bonds offer larger returns in U.S. dollars than those denominated in high interest rate currencies, just the opposite of the traditional carry trade strategy that goes long in high short-rate and short in low short-rate currencies using short-term instruments.

We estimate an affine model, with global and idiosyncratic shocks, that prices defaultable bonds across currencies and maturities. To replicate our empirical findings, our estimates imply that the exposure to the global shock must be inversely related to the loading on the global state. This novel restriction on the stochastic discount factors (SDFs) of domestic and foreign investors implies that the volatility of the permanent component of the SDFs must be different for low and high interest rate currencies. This further differentiates emerging markets from advanced economies. In fact, for the latter, Lustig et al. (2019) showed that the volatility of the permanent component of investors' SDFs must be equalized in order for term premiums to offset currency premiums.

To understand the economic implications of our empirical findings, we decompose returns in components associated with currency, default, and term premiums, and show that the local currency term premium drives bond excess returns. The default premium is positive for all countries; does not change with bond maturities; and contributes to the level, but not to the slope, of carry trade returns because it is similar for low and high interest rate currencies for maturities longer than one year. Our results confirm the connection between currency and bond risk premiums also for less developed financial markets.

Governments can issue bonds in local or foreign currency, and they typically do both. While governments in advanced economies issue most of the bonds in their own currency, those in emerging markets issue bonds in both local currency and foreign currency, mostly U.S. dollars. Traditionally, foreign investors bought only emerging market

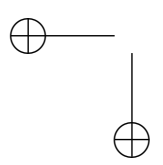




$$
\text { "em port'final" — 2021/5/3 - 12:15 — page } 3 \text { - \#3 }
$$

government bonds in foreign currency. This is the so-called "original sin" (Eichengreen et al., 2003). However, emerging market government bonds in local currency have recently attracted considerable attention from foreign investors and are a growing global asset class, as well as a primary form of financing for many governments.

The main risks for foreign investors buying advanced economy government bonds are currency and interest rate risks. While the currency premium explains most of the bond returns with short maturity, the term premium is increasingly important to explain the returns of longer maturity bonds. The default premium, especially for short maturity bonds, is assumed to be negligible. In contrast, for foreign investors in emerging market government bonds, the default premium is an additional source of risk, while the currency premium is relevant only for bonds issued in local currency, and captures the risk of debt monetization.

In this paper, we focus on emerging market government bonds issued in local currency with different maturities, ranging from 3 months to 10 years. We consider bonds issued by 17 emerging markets included in the J.P. Morgan GBI-EM index, an investable index for emerging market government bonds in local currency. Because we are interested in the term structure of carry trade returns, we cannot use bond indexes which, for each country, pool together bonds with different maturities. We build, instead, the term structure of bond returns for a holding period of 1 month from zero-coupon yield curves based on individual bonds in local currency.

We propose a novel decomposition of the risk premium to foreign investors in four components: the (local currency) term premium; the (local currency) default premium; the short-term interest rate differential; and the expected change in the exchange rate. The sum of the term premium and the default premium corresponds to the bond excess returns in local currency. The sum of the short-term interest rate differential and the expected change in the exchange rate corresponds to the currency premium. Because emerging market bonds have sizeable default risk, in order to obtain this decomposition we use the methodology in Du and Schreger (2016) to construct default-free returns from zero-coupon yield curves in local currency by swapping dollar cash flows from default-free U.S. Treasury bonds into the local currency using cross-currency swaps with negligible counterparty risk.

We start by describing the unconditional decomposition of carry trade returns for the median emerging market, pooling together all countries and monthly observations. All components of the decomposition significantly contribute to the returns to foreign investors. The median emerging market has an annual short-term interest rate higher than the United States, approximately equal to $3.5 \%$, partly balanced by
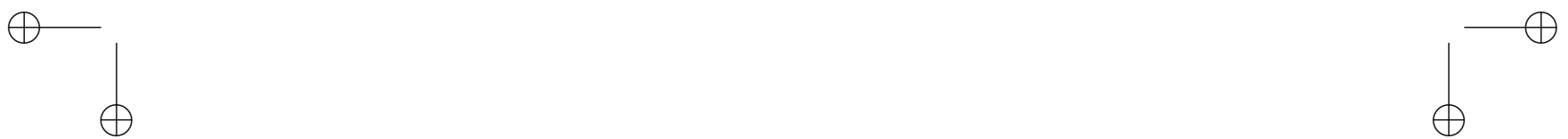
a currency which depreciates on average $2.5 \%$ per year, which leads to an average currency excess return of $1 \%$. For the term and default premiums, we study the term structure from 3 to 120 months. At a maturity of 60 months, the median term premium is approximately $2 \%$, and the median default premium $1.3 \%$. While the curve for the default premium is approximately flat around $1 \%$, the term premium increases from $0.0 \%$ to $3.6 \%$.

We then turn to cross-sectional evidence, and describe the properties of portfolios sorted by one of the strongest predictors of currency returns: the short-term interest rate. We group bonds with a maturity of 5 years in four portfolios rebalanced monthly: the first portfolio contains countries with the lowest short-term interest rate, and the last portfolio countries with the highest short-term interest rate. First, we find a declining cross-section of term premiums, that more than offsets the increasing cross-section of currency excess returns. Default premiums are positive for all portfolios and, therefore, further increase the difference between currency returns and bond excess returns in dollars. However, default premiums are similar for low and high-interest rate portfolios and do not contribute to long/short returns for maturities longer than one year. These results indicate the existence of a connection between a predictor of currency excess returns and term premiums. Similarly, we show that portfolio sorted by the yield curve slopes, a strong predictor of bond returns, offer a cross-section of term premiums.

Our results are related to, but different from, those in Lustig et al. (2019), which also considered carry trade returns with long-term government bonds, but for a set of advanced economies, and therefore assumed no default risk. For advanced economies, sorting countries by short-term interest rates produces a cross-section of currency excess returns, which is fully offset by a cross-section of bond excess returns in local currency. The focus of our paper is on emerging market government bonds, and one might think that a default premium drives their returns. We decompose bond excess returns in local currency in two components: the term premium and the default premium. We find a cross-section of term premiums that goes in the same direction as for advanced economies, but larger in magnitude. The default premium is positive and contributes to bond excess returns in local currency, but does not affect carry trade returns because it is not related to short-term interest rates. Therefore, carry trade returns using advanced and emerging market government bonds are different. For emerging markets, bond excess returns in dollars are positive and are driven by the term premium, which is large and increasing with maturity.

We estimate a factor model to identify the common factors that could explain the cross-section of the local currency term premium, as its properties, for emerging market government bonds, have yet to be

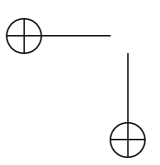




$$
\text { "em port'final" — 2021/5/3 - 12:15 — page } 5 \text { - \#5 }
$$

explored. We exploit the full term structure, and consider as test assets a large set of portfolios containing bonds with maturity of $3,12,36$, and 60 months. We find that the cross-sectional variation in the term premium is explained by covariances with two risk factors. The first factor, which we denote the U.S. term premium factor, is the first principal component extracted form the term structure of U.S. government bond excess returns; the second factor, which we denote the low-minus-high term premium factor, is the return of the zero-cost portfolio that goes long in the low interest rate currencies and short in the high interest rate currencies for the benchmark maturity of 60 months. Our results extend the evidence of deep connection between currency and bond premiums also for emerging market government bonds. Regarding the remaining components of emerging market government bond returns in dollars, Lustig et al. (2011) showed that currency premiums are explained by global factors, while Du and Schreger (2016) showed that domestic factors are important contributor to local currency credit spreads.

Motivated by our empirical findings, we introduce default risk in an otherwise standard affine model for the term structure of bond returns. In the model, heterogeneity in the exposure to country-specific risk cannot explain the cross-section of bond returns, as investors' portfolios are well diversified, and any country-specific risk is averaged out. On the contrary, heterogeneity in the exposure to aggregate risk can explain the cross-section of bond returns uncovered in the data.

For a holding period of 1 month, the default-free bill returns in dollars coincide with currency excess returns. In this case, Lustig et al. (2011) showed that one source of heterogeneity across countries, namely, the exposure to a global shock, is sufficient to replicate the observed crosssection of currency premiums: countries with a higher (lower) exposure to the global shock have lower (higher) short-term interest rates and offer lower (higher) currency premiums. For the model to generate also a large cross-section of term premiums, we show that is sufficient to introduce a second source of heterogeneity, namely, the loading on the global state. Specifically, for term premiums to more than offset currency premiums and, thus, obtain negative carry trade returns, the exposure to the global shock must be inversely related to the loading on the global state. This is a novel restriction on the SDFs of domestic and foreign investors with an interesting economic implication: the volatility of the permanent component of the SDFs must be different for emerging countries with low and high short-term interest rates. Our result extends the main finding in Lustig et al. (2019) according to which the volatility of the permanent component of investors' SDFs must be equalized across advanced economies.

When the risk of default is affected by global shocks, then average bond returns are higher because of the default premium. Since in our 
sample we do not observe a cross-section of default premiums, we assume the same loadings on the global shock for the default process of all countries. Similarly, we also assume that emerging markets do not differ in terms of the inflation process. While heterogeneity in the inflation process can also produce a cross-section of nominal variables, for example, the term premium, it would not affect real variables. This would be counterfactual since we observe a cross-section of real interest rates in our sample.

The literature on sovereign bonds has explored different components of bond risk premiums. First, the currency literature shows that currency returns are large and are explained by global factors. Lustig et al. (2011) find that carry trade returns are explained by one single "slope" risk factor, Carry, related to global equity market volatility. ${ }^{1}$ Second, the default risk literature, both theoretical and empirical, has mostly focused on bonds in foreign currency (see Aguiar et al. (2016) for an excellent review). Borri and Verdelhan (2011), Longstaff et al. (2011), and Ang and Longstaff (2013) find that a large fraction of the excess returns on government bonds in dollars represents compensation for aggregate U.S. market risk. Du and Schreger (2016) study the local currency credit risk of emerging market government bonds by creating a synthetic local currency risk-free rate using U.S. Treasury bonds and currency swaps in order to hedge currency risk. We use the same methodology to build default-free yield curves for all the countries included in the J.P. Morgan GBI-EM index and focus on the term premium component. Third, the term structure literature has mostly focused on advanced economies. One strand of the literature focused on common factors (Cochrane and Piazzesi, 2005; Fama and French, 1993; Litterman and Scheinkman, 1991), and another on market frictions and inefficiencies (Du et al., 2018a; Guibaud et al., 2013; Krishnamurthy and Vissing-Jorgensen, 2012). Recent work analyzed the term structure of risk premiums in equity markets (Van Binsbergen et al., 2012), real estate markets (Giglio et al., 2014), and volatility markets (Dew-Becker et al., 2017). Backus et al. (2018) provide a general analysis of the term structure of asset returns for a large set of assets. We focus on the term structure of emerging market bond excess returns in local currency and analyze its two components: the term premium and the default premium. A growing theoretical literature attributes countries' differences in exposure to global risk to size (Hassan, 2013); monetary policy (Backus et al.,

1 Additional relevant papers are Farhi et al. (2009), who find that disaster risk accounts for more than one-third of currency risk premiums in advanced countries; Lettau et al. (2014), who find that a conditional downside-risk capital asset pricing model explains excess returns on currency, equity, commodities, and sovereign bond portfolios; Della Corte et al. (2016), who show that a global imbalance risk factor explains currency risk premiums; and Bansal and Dahlquist (2000) and Hassan and Mano (2014), who argue that highly persistent differences across countries mostly explain carry trade currency risk premiums.

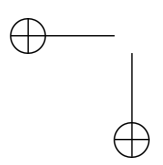




$$
\text { "em port'final" — 2021/5/3 — 12:15 — page } 7 \text { - \#7 }
$$

Global Risk in Long-Term Sovereign Debt

2010); exposure to growth news shocks (Colacito et al., 2018); and bond convenience yield differentials due to the interaction of monetary and fiscal policy (Valchev, 2020). In particular, Ready et al. (2017) show that differences in exposure to global shocks depend on the commodity export intensity, which are key characteristics of most emerging countries. We build on work by Alvarez and Jermann (2005); Bansal and Lehmann (1997); Hansen and Scheinkman (2009) and Sandulescu et al. (2018), and decompose the SDFs of emerging market investors into permanent and transitory components using long-term bonds, and show that the volatility of the permanent component must be different across emerging countries. This novel finding is related to previous work by Aguiar and Gopinath (2007), who find that shocks to trend growth are the primary source of fluctuations in emerging markets.

\section{Bond Returns}

In a standard currency carry trade strategy, investors go long in high-interest rate currencies and short in low-interest rate currencies. According to the standard uncovered interest rate parity (UIP), which assumes risk-neutral investors and no default risk, carry trade expected returns should be equal to zero. Considerable evidence suggests that carry trade returns are instead large and significant. In this paper, we consider carry trade strategies built with emerging market bonds with different maturities, and not Treasury bills (i.e., bonds with shorter maturity), and critically consider returns with the same holding period for all maturities, which we set to 1 month.

\subsection{Building bond returns}

1.1.1 Data. We collect daily frequency par yield curves in local currencies for 17 emerging markets and the United States from Bloomberg. Specifically, we include all the emerging countries in the J.P. Morgan GBI-EM index, an investable index for emerging market government bonds in local currencies ${ }^{2}$. The countries in our sample are Brazil, Chile, China, Colombia, Hungary, India, Indonesia, Malaysia, Mexico, Perù, Philippines, Poland, Romania, Russia, South Africa, Thailand, and Turkey. We also collect, from Bloomberg and for the same set of countries, daily cross-currency swap (CCS) and interest rate swap (IRS) rates for maturities that range from 1 to 10 years. Following the methodology described in Du and Schreger (2016), we use swap rates to

2 The J.P. Morgan GBI-EM indexes track emerging market governments bonds in local currency and include individual bonds that meet specific criteria in terms of liquidity and reliability of market prices. Table A1 in the Internet Appendix shows that, at the 5 -year maturity, the bond returns based on the par yield curves and the J.P. Morgan GBI-EM bond indexes have a correlation of more than 0.90 for most countries, except for the Philippines, which has a lower correlation of 0.51 .

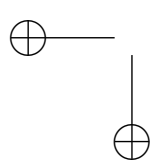


construct synthetic forward rates for maturities longer than one year. Finally, we collect spot and outright forward rates at maturities 1, 3, and 6 months from WM/Reuters through Datastream. Our sample is at the monthly frequency, using end-of-month rates. It runs from April 2005 to May 2019 and is constrained by the availability of swap data and a minimum number of countries required to build portfolios.

1.1.2 Notation. We focus on zero-coupon bonds in local currencies with different maturities. $P_{t}^{(m)}$ is the price at date $t$ of a zero-coupon bond with maturity in $m$ months; $y_{t}^{(m)}$ denotes the corresponding continuously compounded yield: $\log P_{t}^{(m)}=-m y_{t}^{(m)}$. For zero-coupon bonds, the one-period holding return from $t$ to $t+1$ is simply $R_{t+1}^{(m)}=$ $P_{t+1}^{(m-1)} / P_{t}^{(m)}$. We take the perspective of foreign investors, for example, U.S. investors, and denote with $x^{*}$ variables in the local currencies of emerging markets, and with $x^{f}$ variables that are default-free. The log excess return, expressed in dollars, on a position in the emerging market bond in excess of the U.S. short-term risk-free rate is

$$
r x_{t+1}^{(m), \$}=\log \left(\frac{R_{t+1}^{(m), *}}{R_{t}^{(1), \$, f}} \frac{S_{t}}{S_{t+1}}\right)=r_{t+1}^{(m), *}-r_{t}^{(1), \$, f}-\Delta s_{t+1},
$$

where $S$ is the spot exchange rate in units of local currency per U.S. dollar; $\Delta s_{t+1}$ denotes the log exchange rate growth; and $R_{t}^{(1), \$, f}=$ $1 / P_{t}^{(1), \$}$ is the short-term (i.e., a maturity of 1 month) dollar risk-free rate. We decompose the log excess return in dollars into the sum of four components:

$$
\begin{aligned}
r x_{t+1}^{(m), \$} & =\underbrace{\left(r_{t+1}^{(m), *}-r_{t+1}^{(m), *, f}\right)}_{\text {default premium }}+\underbrace{\left(r_{t+1}^{(m), *, f}-r_{t}^{(1), *, f}\right)}_{\text {term premium }}+ \\
& \underbrace{\left(r_{t}^{(1), *, f}-r_{t}^{(1), \$, f}\right)}_{\text {interest rate differential }}-\Delta s_{t+1} .
\end{aligned}
$$

Taking conditional expectations, the four components of (1) have a clear interpretation. The first component denotes the default premium at maturity $m$ in local currency. The second component is the term premium at maturity $m$, also in local currency. The third component is the difference between two default-free short-term rates: the emerging market short-term rate, in local currency, and the U.S. short-term rate, in dollars. The fourth component is the expected change in the exchange rate. In normal conditions, forward rates satisfy the covered interest parity condition and $f_{t}^{(1)}-s_{t} \approx r_{t}^{(1), *, f}-r_{t}^{(1), \$, f}$, where $f_{t}^{(1)}$ is the log of

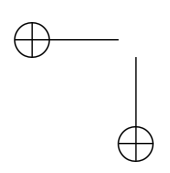




$$
\text { "em port'final" — 2021/5/3 — 12:15 — page } 9 \text { — \#9 }
$$

Global Risk in Long-Term Sovereign Debt

the forward exchange rate. Therefore, the sum of the last two terms in (1) denotes the log currency excess returns $r x_{t+1}^{F X}=f_{t}^{(1)}-s_{t}-\Delta s_{t+1}{ }^{3}$

1.1.3 Synthetic forward rates. Following Du and Schreger (2016), we construct synthetic default-free zero-coupon yields for emerging market government bonds in local currency starting from the covered interest parity (CIP) relationship between government bond yields in emerging markets and the United States. The methodology relies on three assumptions. First, financial markets do not allow riskfree arbitrage. Second, FX forward and swap contracts are free from counterparty risk. Third, U.S. Treasuries are default-free.

The CIP at maturity $m$ implies that

$$
y_{t}^{(m), *, f}-y_{t}^{(m), \$, f}=\frac{1}{m}\left(f_{t}^{(m)}-s_{t}\right)
$$

where $f_{t}^{(m)}$ denotes the log of the forward exchange rate at maturity $m$, while $y_{t}^{(m), *, f}$ and $y_{t}^{(m), \$, f}$ denote the default-free yields at maturity $m$ for emerging market and U.S. government bonds, respectively. We use the outright forward rates for short maturities of 1,3 , and 6 months. For longer maturities, we construct synthetic forward rates using CCS and IRS. Given the log zero-coupon CCS from the fixed local currency rate with maturity $m$ for the 1-month U.S. LIBOR interest rate and the IRS from the fixed dollar rate with maturity $m$ for the U.S. 1-month LIBOR interest rate, the zero-coupon fixed-for-fixed local currency to dollar rate $\rho_{t}^{(m)}$ is equal to the long-term forward premium ${ }^{4}$

$$
\rho_{t}^{(m)}=\frac{1}{m}\left(f_{t}^{(m)}-s_{t}\right)
$$

Finally, we construct the default-free holding-period log return in local currency with maturity $m$ as

$$
r_{t+1}^{(m), *, f}=m y_{t}^{(m), *, f}-(m-1) y_{t+1}^{(m-1), *, f},
$$

3 The term and default premiums correspond to expected excess returns, not yield spreads. As such, the default premium is different from the "local currency credit spread" in Du and Schreger (2016). They constructed their spread as the difference between the yield on risky and default-free bonds. Similarly, the term premium is different from the "slope" of the yield curve, or term spread).

4 Akram et al. (2008) argues that the covered interest parity holds at daily and lower frequencies. In the case that long-dated forward contracts are directly traded, such as the euro/dollar pair, the difference between the CCS and long-term forward is indeed very small (Buraschi et al., 2014). A growing literature studies violations of the covered interest parity and attributes it to the shrinkage of wholesale USD funding of European banks (Ivashina et al., 2015); bank regulatory costs (Du et al., 2018b); and the convenience yield of the U.S. Treasury bonds over other sovereign yields (Du et al., 2018a; Liao, 2020). 


$$
\text { "em"port'final" — 2021/5/3 - 12:15 — page } 10 \text { - \#10 }
$$

where $y_{t+1}^{(m-1), *, f}$ is obtained by interpolation of the default-free yield curve at time $t+1$ based on local currency bonds.

For a given sovereign and maturity, we expect the risky yield to be larger than the default-free yield. However, as also noted in Du and Schreger (2016), this difference, or local currency credit spread, is sometimes negative. Since these instances are a clear violation of the conditions required by Du and Schreger (2016)'s methodology, we exclude them from our sample. Specifically, we set a minimum threshold of $-0.5 \%$ for the local currency credit spread at the 5 -year maturity, and drop the observations below this threshold for bonds at all maturities. We drop $2.4 \%$ of the monthly observations for the 5-year maturity because of this requirement (see Table A3). The Internet Appendix presents two sets of results to support our choice. First, Section C shows that excluded observations correspond to periods of exceptionally low liquidity for the swap instruments used to build the default-free yields. Second, in Section D, we validate our swap-based measure of default-free yields in local currencies by comparing it with a measure constructed from bonds in local currencies issued by supranational issuers with AAA credit ratings. We prefer the swap-based measure because it allows for better coverage both in terms of currencies and in terms of time, while the supranational-based measure cannot be generalized for all sample countries and is subject to the lower liquidity of these bonds compared to U.S. Treasury bonds or cross-currency swap rates.

1.1.4 Term structure of bond returns. We start by describing the decomposition of unconditional bond risk premiums, pooling together all countries and monthly observations. In the decomposition in (1), the only components that change with the maturity are the term and default premiums. Figure 1 plots these two components as function of maturity for the median emerging market, along with the term premium for the United States (the dark- and light-gray bands correspond, respectively, to one- and two-standard-error bands around the point estimates). The figure illustrates that both the level and the slope of the term premium are similar between the median emerging market and the U.S. market. The term premium increases, in both cases, from approximately $0 \%$ (at a maturity of 3 months) to $4 \%$ (at a maturity of 10 years). Additionally, for emerging market government bonds the default premium is equal to approximately $1 \%$ at all maturities.

1.1.5 Portfolios. We then turn to the cross-sectional evidence. We form portfolios using two strong predictors of currency and bond returns: short-term interest rates or yield curve slopes. At the end of each month $t$, we allocate all countries $i=1, \ldots, I$ to four portfolios $\mathrm{j}=1, \ldots, 4$, and consider a holding period of 1 month. The first set of portfolios is

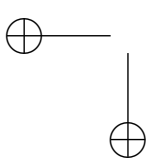




$$
\text { "em port"final" — 2021/5/3 — 12:15 — page } 11 \text { — \#11 }
$$

Global Risk in Long-Term Sovereign Debt

Figure 1

Bond Return Components at Different Maturities (U.S. vs Emerging Markets)

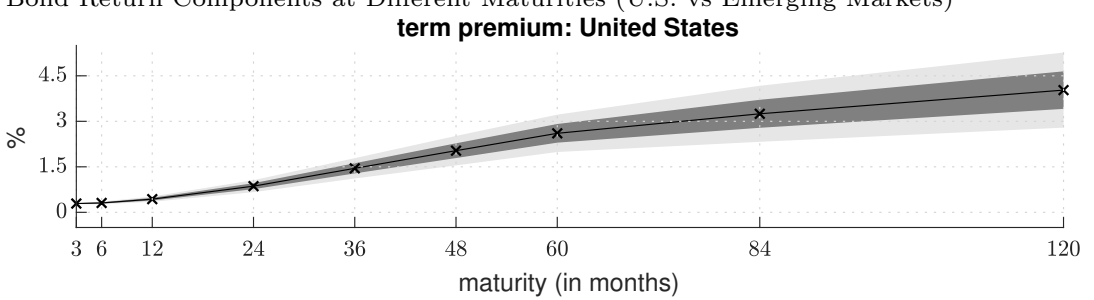

term premium: emerging markets (median)

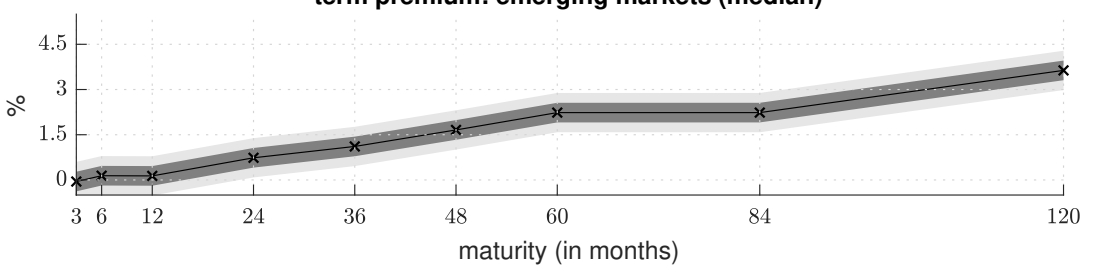

default premium: emerging markets (median)

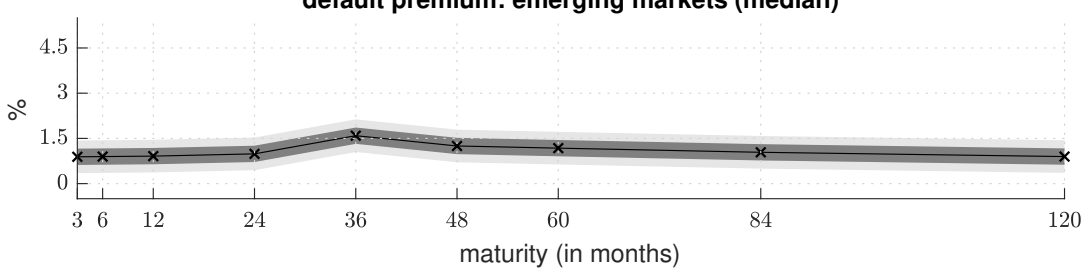

This figure plots the average term premium as a function of bond maturity for the U.S. and median emerging markets. For the median emerging market, the figure also plots the average default premium. For emerging markets, we compute the average term and default premiums for each country and then plot the median values. The term and default premium are defined in Equation (1). Returns are annualized and in percentages. The darkgray-shaded band corresponds to a one-standard-error interval around the point estimates; the light-gray-shaded band corresponds to the $95 \%$ confidence interval. Standard errors are by bootstrap. Data are monthly from WM/Reuters and Bloomberg for the period April 2005 to May 2019.

sorted by the 1-month forward discounts, a proxy of the short-term interest rate differential with respect to the United States For this sort, portfolio 1 contains countries with the lowest short-term interest rates, and portfolio 4 contains countries with the highest short-term interest rates. The second set of portfolios is sorted by the risky yield curve slopes. For this sort, portfolio 1 contains countries with relatively steep yield curves, while portfolio 4 countries with relatively flat yield curves. Note that in the construction of portfolios, we only use information available to investors up to time $t$. We then compute the log bond excess return in dollars $\left(\overline{r x}_{t+1}^{(m), \$, j}\right)$ for portfolio $j$ by taking the average of the $\log$ bond excess returns in each portfolio $j$ 


$$
\text { "em"port'final" — 2021/5/3 - 12:15 — page } 12 \text { — \#12 }
$$

$$
\overline{r x}_{t+1}^{(m), \$, j}=\frac{1}{N_{j}} \sum_{\{i\} \in P_{j}} r x_{t+1}^{(m), \$, i} .
$$

The number of assets in our portfolios varies over time. We have a total of 5 assets at the beginning of the sample in April 2005 and 14 at the end of May 2019. The maximum number of assets attained during the sample is 17 .

\subsection{Returns to bond speculation for a U.S. investor}

We start by considering the strategy of foreign investors that borrow at the U.S. short-term rate to buy emerging market government zerocoupon bonds in local currency. We consider the benchmark maturity of 5 years (i.e., 60 months), which is the average duration of the J.P. Morgan GBI-EM index, and focus on a holding-period of 1 month. We then discuss results for the entire term structure in Section 1.3.

Table 1 presents the characteristics of two sets of portfolios: four portfolios sorted by short-term interest rates and four portfolios sorted by yield curve slopes. For each sort, the table illustrates the portfolio excess returns in dollars, as well as the portfolio returns associated to the four components identified in Equation (1): that is the default premium; the term premium; the short-term interest rate differential; and the expected exchange rate growth. In each panel, we report averages, standard deviations, and standard errors. Because all components are constructed from tradable instruments, investors can buy or sell each of the four components. The table also illustrates the returns of the lowminus-high $(L M H)$ portfolios 1-4, which goes long in portfolio 1 and short in portfolio 4 .

We start with the description of the portfolios sorted by short-term interest rates, proxied by the forward discounts. Portfolio 1 contains countries with the lowest short-term interest rates, while portfolio 4 countries with the highest short-term interest rates. On average, the annual short-term interest rate differential, with respect to the United States is equal to $3.5 \%$. Portfolios offer a monotonically increasing crosssection of exchange rate growth. This is the standard violation of the UIP, explored by the literature on the currency premium. Currency excess returns are equal to the difference between the forward discount (second panel) and the exchange rate growth (third panel): on average approximately $1 \%$ per annum. The fourth panel shows that the mean term premium decreases monotonically from $4.88 \%$ to $-1.38 \%$ per annum. Since emerging market government bonds are not default-free, we additionally need to account for the default premium. The fifth panel shows that the default premium is, on average, approximately equal to $1.3 \%$, and statistically different from zero for all portfolios except for

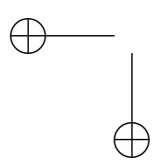




$$
\text { "em'port'final" — 2021/5/3 - 12:15 — page } 13 \text { — \#13 }
$$

Global Risk in Long-Term Sovereign Debt

the second. Finally, the last panel shows that bond excess returns in dollars are positive for all portfolios, and statistically different from zero except for portfolio 4 . The $L M H$ strategy long in portfolio 1 and short in portfolio 4 offers a dollar excess return of $4.61 \%$ per annum, with a Sharpe ratio of $33 \%$, comparable to the Sharpe ratio of U.S. equity markets. Note that a traditional currency carry trade strategy would be just the opposite: long in portfolio 4 (high short-rate currencies) and short in portfolio 1 (low short-rate currencies). The three components highlighted in (1) contribute to $L M H$ bond excess returns in dollars as follows: (a) the term premium is large and equal to $6.26 \%$; (b) the default premium is negligible and equal to $-0.07 \%$; (c) the currency premium is equal to $-2.06 \%$ and partially offsets the positive contribution of the term premium.

The cross-section of currency premiums is well documented in the literature (e.g. Lustig et al. (2011)). For what concerns the term premium, our results for emerging markets corroborate the findings in Lustig et al. (2019) for advanced economies: also in our sample the cross-section of the term premium goes in the opposite direction with respect to the cross-section of the currency premium. For advanced economies, the two cross-sections cancel out and bond excess returns in dollars are not statistically different from zero. On the contrary, in our sample, the declining cross-section of the term premium more than offsets the increasing cross-section of the currency premium. Because emerging market government bonds in local currency are subject to the risk of default (Du and Schreger, 2016), one might think that the default premium is an important contributor to the term structure of carry trade returns. Our results show that this is not the case: the default premium does not contribute to the cross-section of bond returns in dollars, but only to their level, because, although positive for all portfolios, the default premium is similar for low and high interest rate currencies. Section F.V in the Internet Appendix presents evidence that this result holds also when the default premium is built from bonds issued by supranational issuers with AAA credit ratings.

We now present the characteristics of portfolios sorted by yield curve slopes. Portfolio 1 contains countries with a steeper yield curve, and portfolio 4 contains countries with a flatter yield curve, with respect to the slope of the U.S. yield curve. We measure the slope of the yield curve as the difference in the risky yields of zero-coupon bonds with a maturity of 5 years and 1 year. We obtain a monotonic cross-section of the term premium, from $2.77 \%$ on the first portfolio to $-0.21 \%$ on the last portfolio. The default premium is always positive and statistically different from zero for all portfolios except for the third. The fact that the default premium is significantly larger for emerging markets with a steeper yield curve (e.g., portfolio 1) implies that the slope of the (risky) 


$$
\text { "em port'final" — 2021/5/3 — 12:15 — page } 14 \text { — \#14 }
$$

Review of Asset Pricing Studies / v 00 n 02015

yield curve contains information on the default risk. On the contrary, for this set of portfolios, we do not obtain a cross-section of currency premiums. Bond excess returns in dollars are positive for all portfolios (and significant for all portfolios except for the last), and the spread in average returns between the first and last portfolios is equal to $4.73 \%$.

Table 1

Bond portfolios: U.S. investor

\begin{tabular}{|c|c|c|c|c|c|c|c|c|c|c|}
\hline \multirow[b]{2}{*}{ Portfolio } & \multicolumn{5}{|c|}{ Sorted by short-term interest rates } & \multicolumn{5}{|c|}{ Sorted by yield curve slopes } \\
\hline & 1 & 2 & 3 & 4 & $1-4$ & 1 & 2 & 3 & 4 & $1-4$ \\
\hline & \multicolumn{5}{|c|}{ Relative slope: $\Delta y_{t}^{(60-12), \$}-\Delta y_{t}^{(60-12), *}$} & \multicolumn{5}{|c|}{ Relative slope: $\Delta y_{t}^{(60-12), \$}-\Delta y_{t}^{(60-12), *}$} \\
\hline Mean & -0.16 & -0.08 & -0.13 & 0.35 & -0.51 & -0.97 & -0.26 & 0.14 & 0.82 & -1.79 \\
\hline$S D$ & 0.60 & 0.67 & 0.73 & 0.55 & 0.64 & 0.68 & 0.61 & 0.55 & 0.51 & 0.62 \\
\hline \multirow[t]{2}{*}{$S E$} & {$[0.05]$} & {$[0.05]$} & {$[0.05]$} & {$[0.04]$} & {$[0.05]$} & {$[0.05]$} & {$[0.05]$} & {$[0.04]$} & [0.04 ] & {$[0.05]$} \\
\hline & \multicolumn{5}{|c|}{ Forward discount: $f_{t}-s_{t}$} & \multicolumn{5}{|c|}{ Forward discount: $f_{t}-s_{t}$} \\
\hline Mean & -0.71 & 1.96 & 4.22 & 8.54 & -9.25 & 3.13 & 3.08 & 3.29 & 5.62 & -2.49 \\
\hline$S D$ & 0.48 & 0.44 & 0.50 & 0.62 & 0.66 & 0.81 & 0.78 & 0.60 & 0.63 & 0.99 \\
\hline \multirow[t]{2}{*}{$S E$} & {$[0.04]$} & {$[0.03]$} & {$[0.04]$} & {$[0.05]$} & {$[0.05]$} & {$[0.06]$} & {$[0.06]$} & {$[0.05]$} & {$[0.05]$} & {$[0.08]$} \\
\hline & \multicolumn{5}{|c|}{ Exchange rate growth: $\Delta s_{t+1}$} & \multicolumn{5}{|c|}{ Exchange rate growth: $\Delta s_{t+1}$} \\
\hline Mean & -0.51 & 0.85 & 2.80 & 6.68 & -7.19 & 2.67 & 1.12 & 1.67 & 5.04 & -2.37 \\
\hline$S D$ & 6.96 & 8.29 & 9.55 & 11.50 & 8.48 & 9.39 & 8.63 & 8.99 & 9.93 & 6.62 \\
\hline \multirow[t]{2}{*}{$S E$} & {$[0.55]$} & [0.64 ] & {$[0.75]$} & [0.91] & {$[0.63]$} & {$[0.73]$} & {$[0.66$ ] } & {$[0.69]$} & {$[0.76]$} & {$[0.52]$} \\
\hline & \multicolumn{5}{|c|}{ Term premium: $r_{t+1}^{(60), *, f}-r_{t+1}^{(1), *, f}$} & \multicolumn{5}{|c|}{ Term premium: $r_{t+1}^{(60), *, f}-r_{t+1}^{(1), *, f}$} \\
\hline Mean & 4.88 & 2.15 & 2.18 & -1.38 & 6.26 & 2.77 & 2.83 & 1.87 & -0.21 & 2.98 \\
\hline$S D$ & 5.38 & 4.33 & 5.36 & 7.16 & 6.60 & 6.36 & 5.93 & 5.28 & 5.10 & 6.16 \\
\hline \multirow[t]{2}{*}{$S E$} & {$[0.42]$} & {$[0.33]$} & {$[0.40]$} & {$[0.55]$} & {$[0.49]$} & {$[0.48]$} & {$[0.45]$} & {$[0.40]$} & {$[0.40]$} & {$[0.47]$} \\
\hline & \multicolumn{5}{|c|}{ Default premium: $r_{t+1}^{(60), *}-r_{t+1}^{(60), *, f}$} & \multicolumn{5}{|c|}{ Default premium: $r_{t+1}^{(60), *}-r_{t+1}^{(60), *, f}$} \\
\hline Mean & 1.16 & 0.20 & 2.62 & 1.23 & -0.07 & 2.62 & 2.00 & 0.05 & 0.89 & 1.73 \\
\hline$S D$ & 4.36 & 5.25 & 4.76 & 4.25 & 5.72 & 5.14 & 4.60 & 4.60 & 4.45 & 6.47 \\
\hline \multirow[t]{2}{*}{$S E$} & {$[0.34]$} & {$[0.41]$} & {$[0.35]$} & {$[0.34]$} & {$[0.43]$} & {$[0.39]$} & {$[0.36]$} & {$[0.35]$} & {$[0.34]$} & {$[0.50]$} \\
\hline & \multicolumn{5}{|c|}{ Bond dollar excess returns: $r x_{t+1}^{(60), \$}$} & \multicolumn{5}{|c|}{ Bond dollar excess returns: $r x_{t+1}^{(60), \$}$} \\
\hline Mean & 5.81 & 3.40 & 6.06 & 1.20 & 4.61 & 5.67 & 6.63 & 3.39 & 0.94 & 4.73 \\
\hline$S D$ & 9.14 & 11.08 & 13.28 & 17.18 & 14.01 & 14.24 & 12.10 & 11.16 & 13.82 & 10.69 \\
\hline$S E$ & {$[0.73]$} & {$[0.85]$} & {$[1.00]$} & [ 1.33$]$ & {$[1.10$ ] } & [ 1.10 ] & [ 0.93$]$ & {$[0.85]$} & [ 1.06 ] & {$[0.80]$} \\
\hline
\end{tabular}

This table reports, for each portfolio and the low-minus-high portfolios 1-4 (i.e., long in portfolio 1, short in portfolio 4) the means, standard deviations, and standard errors for the yield curve slopes; the forward discounts; the exchange rate growth; the term premium; the default premium; and the bond excess returns in dollars. Emerging market government bonds are zero coupon with a maturity of 5 years. The first set of four portfolios is formed by sorting countries by the short-term interest rates, proxied by the forward discounts. The second set of four portfolios is formed by sorting countries by the yield curve slopes. We measure the slope of the yield curve as the difference in the yields for risky zero-coupon bonds with a maturity of 5 years and 1 year $\left(\Delta y_{t}^{(60-12)}\right)$. The standard errors, reported in brackets, are by bootstrap. All moments are annualized and reported in percentage points. Data are monthly, from WM/Reuters and Bloomberg. The sample period is April 2005 to May 2019.

To summarize the portfolios results, Figure 2 plots the cumulative $L M H$ bond returns in dollars (solid-blue line), along with the $L M H$ currency premium (dashed-red line), LMH term premium (dasheddotted magenta line), and $L M H$ default premium (dotted-black line). 


$$
\text { "em port'final" — 2021/5/3 — 12:15 — page } 15 \text { — \#15 }
$$

Global Risk in Long-Term Sovereign Debt

We first describe the results for portfolios sorted by the short-term interest rates (top panel). First, the cumulated returns in dollars from going long in bonds of low interest rate currencies and short in bonds of high interest rate currencies are approximately equal to $60 \%$ in the period April 2005 to May 2019. These dollar returns increased steeply up to - roughly - the middle of the Great Recession, highlighted by a gray-shaded area; then, they first declined sharply and eventually resumed their growth at a relatively slower rate. Second, we look at the contribution of each of the components of bond returns in dollars. The $L M H$ default premium has been roughly flat and close to zero during the whole sample. On the contrary, the $L M H$ term and currency premiums have moved in opposite directions. In fact, the cumulative term premium returns have been approximately equal to $90 \%$, while the cumulative currency returns have been approximately equal to $-30 \%$. Therefore, the evolution of the term premium accounts for most of the evolution of the dollar returns.

Also for portfolio sorted by yield curve slopes (bottom panel), $L M H$ cumulative returns in dollars are large and approximately equal to $66 \%$. However, for this sort, the default premium is a positive contributor to dollar returns $(26 \%)$, while the contribution of the currency premium is negligible. The term premium, then, accounts for $40 \%$ of the cumulated bond dollar excess returns.

\subsection{The term structure of bond risk premiums}

The previous section presented the properties of portfolios of emerging market government bonds, for the benchmark maturity of 5 years, sorted by short-term interest rates or yield curve slopes. In this section, we focus on the first sort, but expand the analysis to the entire term structure, considering bonds with maturities from 3 to 120 months.

Figure 3 plots, for all portfolios, the averages of the term premium; the default premium; the currency premium; and the excess returns in dollars, for maturities from 3 to 120 months. We summarize the main results as follows. First, we find a declining cross-section for the term premium at all maturities, except for bonds with a maturity of 3 months for which the term premium is flat. Second, we observe that the average level of the term premium increases with maturity: it is equal to zero at a maturity of 3 months, and to $3.6 \%$ at a maturity of 120 months. Third, the average default premium is positive and similar for all portfolios and maturities, except for the second portfolio at a maturity of 120 months, which has a negative mean default premium. Fourth, the average bond excess returns in dollars are positive at all maturities and for all portfolios, with the level increasing with maturity. Forward discounts and exchange rate growth, and thereby the currency

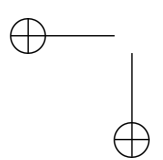




$$
\text { "em port'final" — 2021/5/3 — 12:15 — page } 16 \text { — \#16 }
$$

Figure 2

$L M H$ cumulative returns
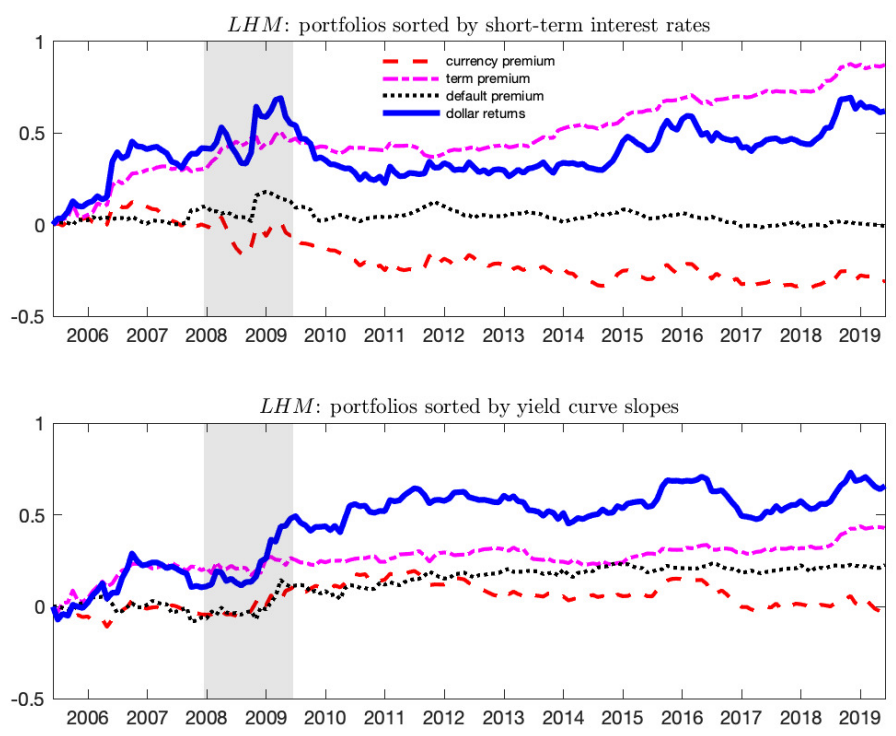

This figure plots the cumulative $L M H$ returns in dollars (solid blue line), along its three components: the $L M H$ currency premium (dashed red line); the $L M H$ default premium (dotted black line); and the $L M H$ term premium (dot-dashed magenta line). Countries are sorted by the short-term interest rates (top panel) or by yield curve slopes (bottom panel). The currency premium is the difference between the short-term interest rate and exchange rate growth components (see Equation (1)). Bond returns are based on emerging market government zero-coupon bonds in local currency with a maturity of 60 months. Data are monthly, from WM/Reuters and Bloomberg, for the period April 2005 to May 2019.

premium, are common across maturities and increase from the first to the last portfolio.

What is the term structure of the $L M H$ bond excess returns in dollars, and of the term and default premium components? Figure 4 plots the $L M H$ bond returns as a function of maturity, from 3 to 120 months. The dark shaded area corresponds to a one-standard-error band around the point estimates; the light grey shaded area corresponds to the $95 \%$ confidence interval. The top panel plots the term premium; the middle panel the default premium; and the bottom panel the bond excess returns in dollars. We summarize our results as follows. First, both the $L M H$ term premium and bond excess returns in dollars are increasing with maturity. Specifically, the term premium increases from approximately $0.5 \%$ to $6.5 \%$; the bond excess returns in dollars from $2.5 \%$ to $7.5 \%$. Second, the $L M H$ default premium is roughly flat at zero for maturities of more than 24 months (with the exception of the 
Figure 3

Portfolio term structure
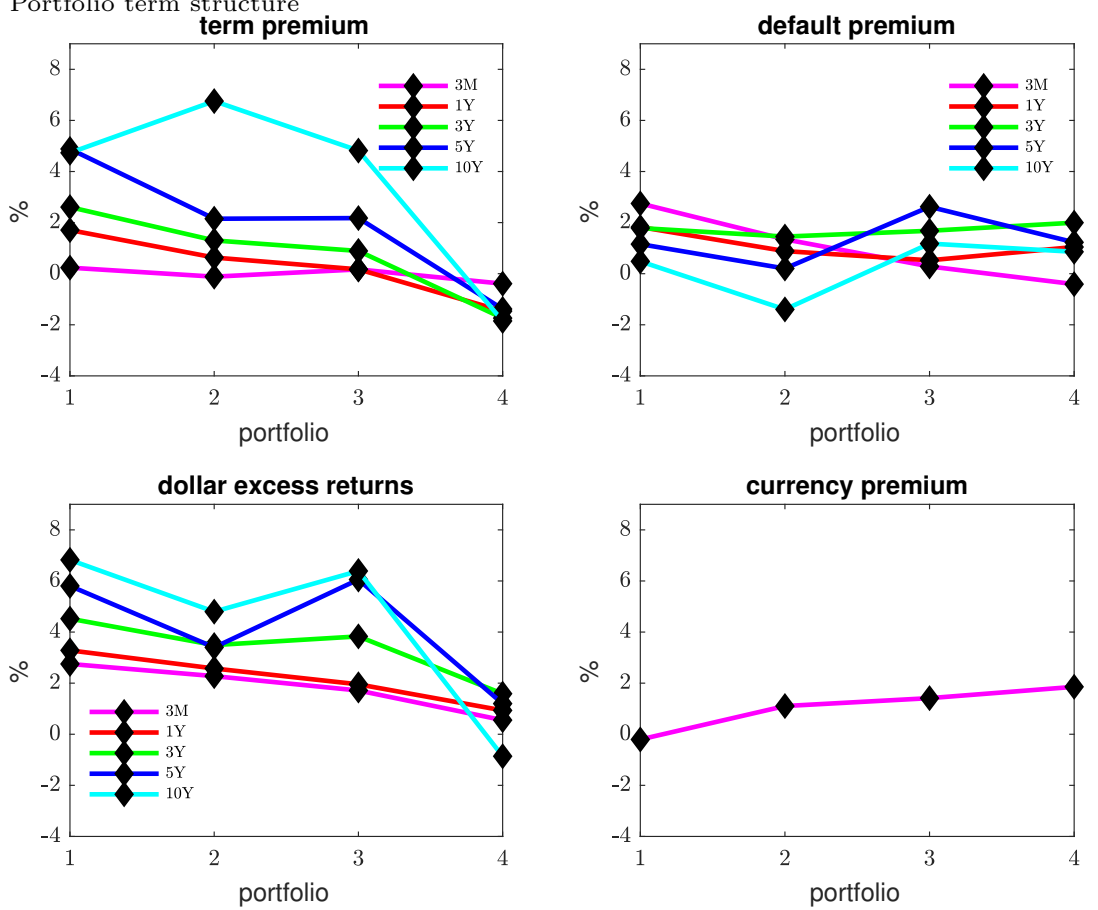

This figure plots the mean term premium; default premium; excess returns in dollars; and currency premium for portfolios sorted by the short-term interest rates. For the term premium, the default premium, and the excess returns in dollars, we consider bonds with maturities of 3 months, 1 year, 3 years, 5 years, and 10 years. All bonds are emerging market government zero-coupon bonds in local currency. All returns are annualized. Data are monthly, from WM/Reuters and Bloomberg, for the period April 2005 to May 2019.

maturity of 84 months), and positive for shorter maturities. For example, the default premium is approximately equal to $3 \%$ at the maturity of 3 months, and approaches zero already at a maturity of 1 year. Finally, we observe that the error bands increase with maturity, as the volatility of the term and default premiums increase.

Our results for emerging markets are related to, but different from, those in Lustig et al. (2019) for advanced economies. In their sample, Lustig et al. (2019) found that the dollar returns of a $L M H$ strategy are weakly increasing, but not statistically different from zero, when countries are sorted by the short-term interest rates. In our sample, the bond excess returns in dollars, for the same $L M H$ strategy, are positive, significant, and increasing with maturity. There are three reasons for this difference. First, recall that the high-minus-low currency carry trade returns are independent of maturity and approximately equal to $2 \%$ in our sample. Second, the default premium is large and positive at short 


$$
\text { "em port'final" — 2021/5/3 — 12:15 — page } 18 \text { — \#18 }
$$

Review of Asset Pricing Studies / v 00 n 02015

maturities, especially on the first and second portfolios, and more than offsets the currency premium. Third, the term premium, while small at short maturities, is increasingly larger at longer maturities and accounts for most of the bond excess returns in dollars at maturities longer than 24 months. In Section 2, we document how, after the Great Recession, the $L M H$ currency premium goes to zero; the importance of the default premium slightly increases; and bond excess returns in dollars are large and significant and almost fully explained by the term premium.

Figure 4

Low-minus-high bond return at different maturities
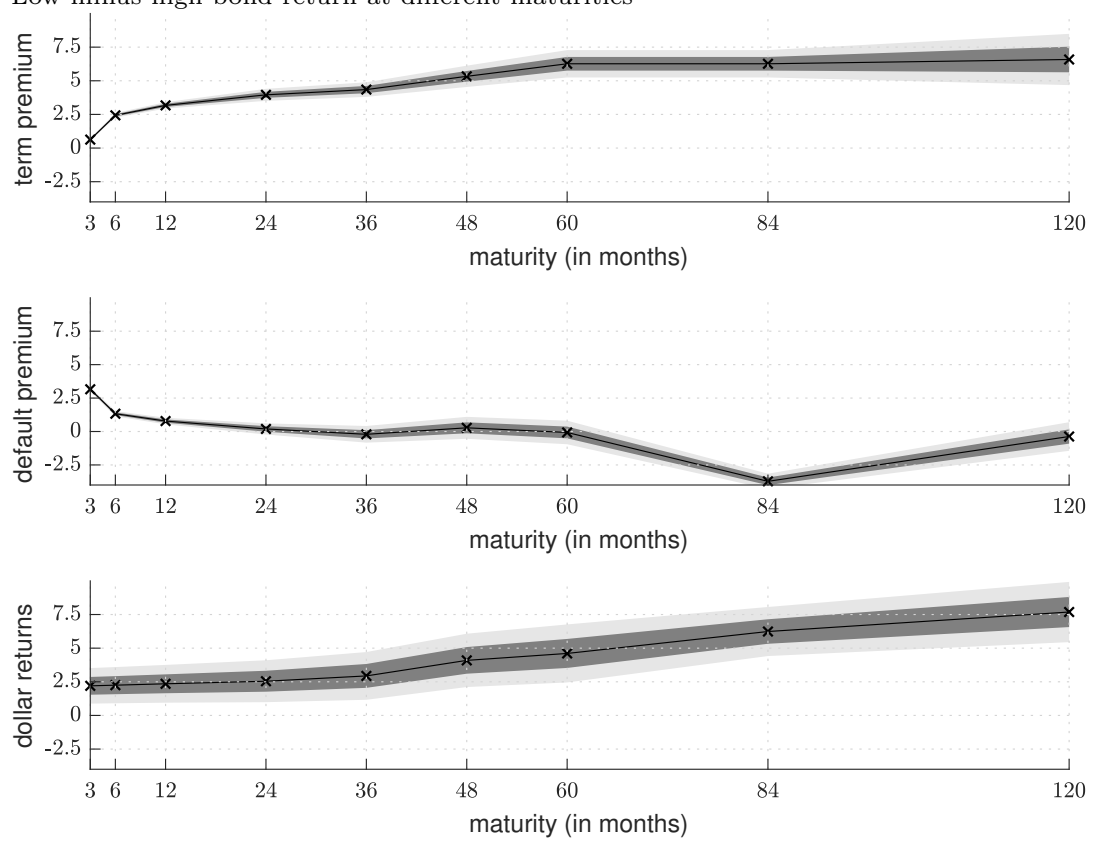

This figure plots $L M H$ bond returns in dollars; the term premium; and the default premium at different maturities. $L H M$ bond returns correspond to a strategy that goes long in portfolio 1 and short in portfolio 4 . Portfolios are formed by sorting countries by short-term interest rates. The holding period is 1 month, and returns are annualized. The dark-shaded area corresponds to a one-standard-error band around the point estimates; the light-gray-shaded area corresponds to the $95 \%$ confidence interval. Standard errors are by bootstrap. All bonds are government zero-coupon bonds issued by emerging markets in local currency. Data are monthly from WM/Reuters and Bloomberg. The sample period is May 2005 to April 2019.

This section documents that foreign investors in emerging market government bonds in local currency can earn large returns with annualized Sharpe ratios comparable to those for the U.S. equity market. 


$$
\text { "em port'final" — 2021/5/3 — 12:15 — page } 19 \text { — \#19 }
$$

Global Risk in Long-Term Sovereign Debt

These carry trade returns are mostly driven by the term premium. In the next section, we show that a two-factor model explains a large fraction of the variation in the term premium in terms of exposure to aggregate risks.

\subsection{Common factors in bond returns}

In this section, we show that the cross-sectional variation in the term premium is matched by covariances with two risk factors. We focus on the term premium as its properties have yet to be explored for emerging market government bonds in local currency. On the contrary, regarding the other components, Lustig et al. (2011) shows that currency premiums are explained by global factors, while Du and Schreger (2016) shows that domestic factors are important contributor to local currency credit spreads.

We focus on portfolios sorted by short-term interest rates, and a maturity of $3,12,36$, and 60 months. We have a total of 16 portfolios. A principal component analysis reveals that about $80 \%$ of the variation in the term premium is explained by just two components (see Tables A11 and A12 in the Internet Appendix). The first component is closely related to the first principal component of the term structure of U.S. Treasury bond excess returns, which we denote as the U.S. term premium factor $\left(U S_{P C_{1}}\right)$. This is a natural level factor, as the term premium for emerging markets is based on synthetic default-free bonds in local currency which are based on U.S. Treasury bonds and the local currency credit spread. The first component is also highly related to the returns of the zero cost portfolio that goes long in portfolio 1 and short in portfolio 4 for the benchmark maturity of 60 months, which we denote as the $L M H$ term premium factor $\left(L H M_{E M}\right)$. This is a slope factor, that should be related to the cross-section of the term premium.

To estimate the factor prices $\lambda$ and the portfolio betas $\beta$, we use two different procedures: a generalized method of moments estimation (GMM) applied to linear factor models, following Hansen (1982), and a two-state (OLS) estimation following Fama and MacBeth (1973), henceforth FMB (see Section G in the Internet Appendix for details on the estimation procedures as well as for the principal component analysis of the test assets). In the first step, we run a time-series regression of returns on the factors. In the second step, we run a cross-sectional regression of average returns on the betas. We do not include a constant in the second step $\left(\lambda_{0}=0\right)$ and therefore assume that assets with a beta equal to zero must offer zero excess returns.

Table 2 reports the asset pricing results. We always include the two risk factors in the set of test assets as recommended by Lewellen et al. (2010). As a result, the total number of test assets is equal to 18: the sixteen term premium portfolios and the two risk factors: $U S_{P C_{1}}$ and 


$$
\text { "em"port'final" — 2021/5/3 - 12:15 — page } 20 \text { - \#20 }
$$

Review of Asset Pricing Studies / v 00 n 02015

$L H M_{E M}$. The table reports estimates of the market prices of risk $\lambda$ and the factor loadings $b$, the adjusted $R^{2}$, the square root of mean squared errors $(R M S E)$, and the $p$-values of $\chi^{2}$ tests (in percentage points). The market price of the $U S_{P C_{1}}$ is not statistically different from zero. This factor explains the level of returns, but not their cross-section. In contrast, the market price of $L H M_{E M}$ is positive and statistically different from zero. Portfolios with a higher loading on this factor are riskier and, thus, offer higher excess returns. Since the factors are returns, no-arbitrage implies that the risk prices of these factors should equal their average excess returns. For both factors, the no-arbitrage condition is satisfied. The loadings $b$ have a natural interpretation as the regression coefficients in a regression of the stochastic discount factor on the two factors. The $t$-stats on the loading on the slope factor shows that it helps to explain the cross-section of the term premium in a statistically significant way. Overall, pricing errors are small. The RMSE is 114 basis points, and the adjusted $R^{2}$ is approximately $74 \%$. The null that the pricing errors are zero cannot be rejected, in the case of the GMM estimation procedure, for a confidence level of $5 \%$.

The results from the asset pricing estimation indicate that the crosssection of the term premium we uncovered in the data is explained by covariances with common factors. In Section G.III of the Internet Appendix, we additionally present the estimation results of a model with time-varying risk and show that the market prices of risk are higher in bad times for U.S. investors, proxied by low U.S. equity market returns.

\section{Robusteness}

In this section, we consider several extensions to evaluate the robustness of our empirical results. First, we consider the characteristics of bond portfolios sorted by short-term interest rates. We find that portfolios containing countries with higher short-term interest rates are relatively riskier, as they contain countries with relatively higher inflation rates; higher 1-year default probabilities; and higher commodity export shares. Second, we compare the decomposition of portfolio returns presented in Table 1 with portfolios formed using alternative sorts and samples.

\subsection{Characteristics of the bond portfolios}

We focus on the four portfolios sorted by short-term interest rates. Recall that both the term premium and the bond excess return in dollars are larger for the first portfolio (low short-term interest rates) than for the last portfolio (high short-term interest rates); and that differences in the exposure to aggregate risks can explain the cross-section of the term premium. Table 3 presents additional characteristics of these four 


$$
\text { "em port"final" — 2021/5/3 — 12:15 — page } 21 \text { — \#21 }
$$

Global Risk in Long-Term Sovereign Debt

Table 2

Asset pricing: U.S. investor

\begin{tabular}{cccccccc}
\hline \multicolumn{7}{c}{ Risk prices } \\
\hline \multirow{2}{*}{$\lambda_{U M_{1}}$} & 8.90 & $\lambda_{L M H_{E M}}$ & $b_{U S_{P C_{1}}}$ & $b_{L M H_{E M}}$ & $R^{2}(\%)$ & $R M S E$ & $\chi^{2}(\%)$ \\
& {$[5.00]$} & {$[1.75]$} & {$[0.15]$} & {$[0.48]$} & & & 7.04 \\
$G M M_{2}$ & 7.59 & 5.26 & 0.27 & 1.51 & 73.80 & 1.14 & \\
& {$[3.56]$} & {$[1.30]$} & {$[0.11]$} & {$[0.36]$} & & & 6.89 \\
$F M B$ & 8.90 & 3.82 & 0.30 & 1.11 & 86.45 & 0.95 & \\
& {$[4.86]$} & {$[1.77]$} & {$[0.15]$} & {$[0.48]$} & & & 0.00 \\
Mean & $\mathbf{7 . 5 9}$ & $\mathbf{4 . 8 2}$ & & & & & \\
\hline SE & {$[4.81]$} & {$[1.63]$} & & & & & \\
\hline
\end{tabular}

The table reports results from GMM and Fama and MacBeth (1973) asset pricing procedures. The test assets are the term premium component from four bond portfolios for each maturity $(3,12,36$, and 60 months) sorted by short-term interest rates. All bonds are emerging government zero-coupon bonds in local currency. Note that we always include the $U S_{P C_{1}}$ and $L H M_{E M}$ risk factors in the set of test assets as recommended by Lewellen et al. (2010). As a result, the number of test assets is equal to 18 (i.e., $4 \times 4+2) . U S_{P C_{1}}$ is the first principal component extracted from U.S. Treasury excess returns with different maturities. $L H M_{E M}$ is the zero cost portfolio that goes long in portfolio 1 and short in the portfolio 4 for bonds with a maturity of 5 years. Market prices of risk $\lambda$, the adjusted $R^{2}$, the square root of mean squared errors (RMSE), and the $p$ values of $\chi^{2}$ tests on pricing errors are reported in percentage points. $b$ denotes the vector of factor loadings. All excess returns are multiplied by 12 (annualized). Shanken (1992)corrected standard errors are reported in parentheses. We do not include a constant in the second step of the FMB procedure. The standard errors in brackets are Newey et al. (1987) standard errors computed with the optimal number of lags according to Andrews (1991). The $\chi^{2}$ test statistic $\alpha^{\prime} V_{\alpha}^{-1} \alpha$ tests the null that all intercepts are jointly zero. This statistic is constructed from the Newey et al. (1987) variance-covariance matrix (one lag) for the system of equations (see Cochrane (2009)). Data are monthly, from WM/Reuters and Bloomberg through Datastream. The sample period is April 2005 to May 2019. The alphas are annualized and in percentage points.

portfolios to verify whether portfolio 1 is riskier than portfolio 4 along additional dimensions. In fact, if anything, we find the opposite result, that is that portfolio 4 is relatively riskier.

The first panel of the table shows, for each portfolio, the average share of local currency bonds held by foreign investors, using data from Arslanalp and Tsuda (2014). Countries with larger shares of local currency bonds held by foreign investors are more exposed to sudden stop and tail risks (see, e.g. Borri (2018); Mendoza (2010)). In our portfolios, the foreign holding shares are similar for the four portfolios and approximately equal to $40 \%$. In terms of point estimates, the average share of local currency bonds held by foreign investors for the first portfolio is smaller than for the last portfolio.

The second panel of the table reports the average inflation rates, computed as percentage change in year-on-year (YoY) CPI indexes collected from local sources through Datastream. Investors in emerging market bonds in local currency are exposed to the risk that government 


$$
\text { "em"port'final" — 2021/5/3 - 12:15 — page } 22 \text { — \#22 }
$$

Review of Asset Pricing Studies / v 00 n 02015

might inflate away their debt. Inflation rates increase monotonically from approximately $2.45 \%$ per annum in portfolio 1 to $6.2 \%$ in portfolio 4. This evidence is not surprising: we sort countries by nominal shortterm interest rates which are higher in countries with higher inflation rates. Since the cross-section of nominal short-term interest documented in Table 1 is larger than the cross-section of inflation rates, portfolios also offer a cross-section of real short-term interest rates.

The third and fourth panels of the table report the averages for two indicators of default risk: the average 1-year default probabilities, which we estimate using S\&P credit ratings for local currency longterm sovereign bonds and the transition probability matrix of Kealhofer (2003); and the average total debt-to-GDP ratios, using data from Arslanalp and Tsuda (2014). These two measures are related to the level of default risk, and are likely to affect the level of bond yields, but not necessarily bond returns. According to both measures, default risk increases from portfolio 1 to portfolio 4: default probabilities increase from $0.18 \%$ for the first portfolio to $0.37 \%$ for the last portfolio; debt-to-GDP ratios from $37 \%$ to $42 \%$.

The fifth and sixth panels of the table report information on the portfolio "commodity intensity," measured as the commodity share of countries' exports, using data from the WTO Statistics Database. We compute the commodity intensity by taking the ratio of commodities to merchandise in total export. Specifically, in the fifth panel, we consider commodities that include only the "fuel and mining category"; in the sixth panel, we also include "agriculture." In line with the cross-section of currency premiums documented in Section 1, and the results of Ready et al. (2017) who show that commodity-intensive countries are less exposed to global shocks and offer higher average currency returns, we find that the mean commodity shares increase from portfolio 1 to portfolio 4.

Finally, in the last panel of the table, we report the average portfolio turnover, measured as the average number of countries that change portfolio every month. For the first three portfolios, the average turnover is approximately $50 \%$. Turnover is smaller in the last portfolio, and equal to approximately $30 \%$.

In Section F of the Internet Appendix, we further show that Turkey is for most of the sample in the last portfolio (approximately $90 \%$ of the time), and that the portfolio properties documented in Table 1 are robust to excluding Turkey from the sample. In Section F.I in the Internet Appendix, we further present measure of tail-risks for the four portfolios. 


$$
\text { "em port"final" — 2021/5/3 — 12:15 — page } 23 \text { — \#23 }
$$

Global Risk in Long-Term Sovereign Debt

\subsection{Alternative samples}

We now consider two samples. The first starts in April 2005 and ends in May 2019: this is our benchmark sample. The second is a shorter alternative sample that starts after the U.S. Great Recession, in July 2009. For all countries, we consider bonds with a maturity of 60 months. Figure 5 summarizes the results by plotting the averages for the different components of bond excess returns in dollars (i.e., the term premium, the default premium, and the currency premium) for portfolios sorted by short-term interest rates or yield curve slopes. For all samples and sorts, we obtain a declining cross-section for the term premium. The default premium is positive in all samples and sorts, and similar across portfolios. The bond excess returns in dollars are positive for all portfolios, samples, and sorts. Finally, in both samples and sorts, the currency premium increases from portfolio 1 to portfolio 4 .

\section{A No-Arbitrage Model of Long-Term Bond Returns}

We impose a minimal structure by considering a standard no-arbitrage term structure model in which we introduce default risk. As we documented in the empirical part of the paper, the default premium is similar for low and high interest rate emerging market currencies, while the cross-section of the term premium is large and more than offsets currency premiums. With the model, we show the properties of the stochastic discount factors that need to be satisfied in order to replicate these empirical findings.

\subsection{Model}

Following recent applications by Lustig et al. (2011, 2014, 2019) and Verdelhan (2014) we consider a world with $N$ different countries and currencies, where $N$ is large, and where each country issues a set of bonds denominated in local currency with the maturity ranging from 1 to $M$ periods. The novel feature of our model is the introduction of default risk.

In each country $i$, the logarithm of the real SDF $\tilde{m}^{i}$ follows from

$$
-\tilde{m}_{t+1}^{i}=\alpha^{i}+\chi^{i} z_{t}^{i}+\sqrt{\gamma^{i} z_{t}^{i}} u_{t+1}^{i}+\tau^{i} z_{t}^{w}+\sqrt{\delta^{i} z_{t}^{w}} u_{t+1}^{w} .
$$

There is a common (global) state variable, $z_{t}^{w}$, and a country-specific state variable, $z_{t}^{i}$. The global state variable enters the SDF of all investors in $N$ different countries. The country-specific state variable $z^{i}$ appears only in the SDF of country $i$ 's investors. The country-specific innovations, $u_{t+1}^{i}$, and global innovations, $u_{t+1}^{w}$, are i.i.d, mean-zero, variance-one Gaussian shocks; $u_{t+1}^{w}$ is a global shock, common across countries, that is priced similarly in each country up to a scaling factor $\delta^{i}$, while $u_{t+1}^{i}$ is a local shock uncorrelated across countries.

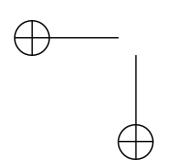




$$
\text { "em port'final" — 2021/5/3 — 12:15 — page } 24 \text { — \#24 }
$$

Figure 5

Bond portfolio returns (alternative samples and sorts)
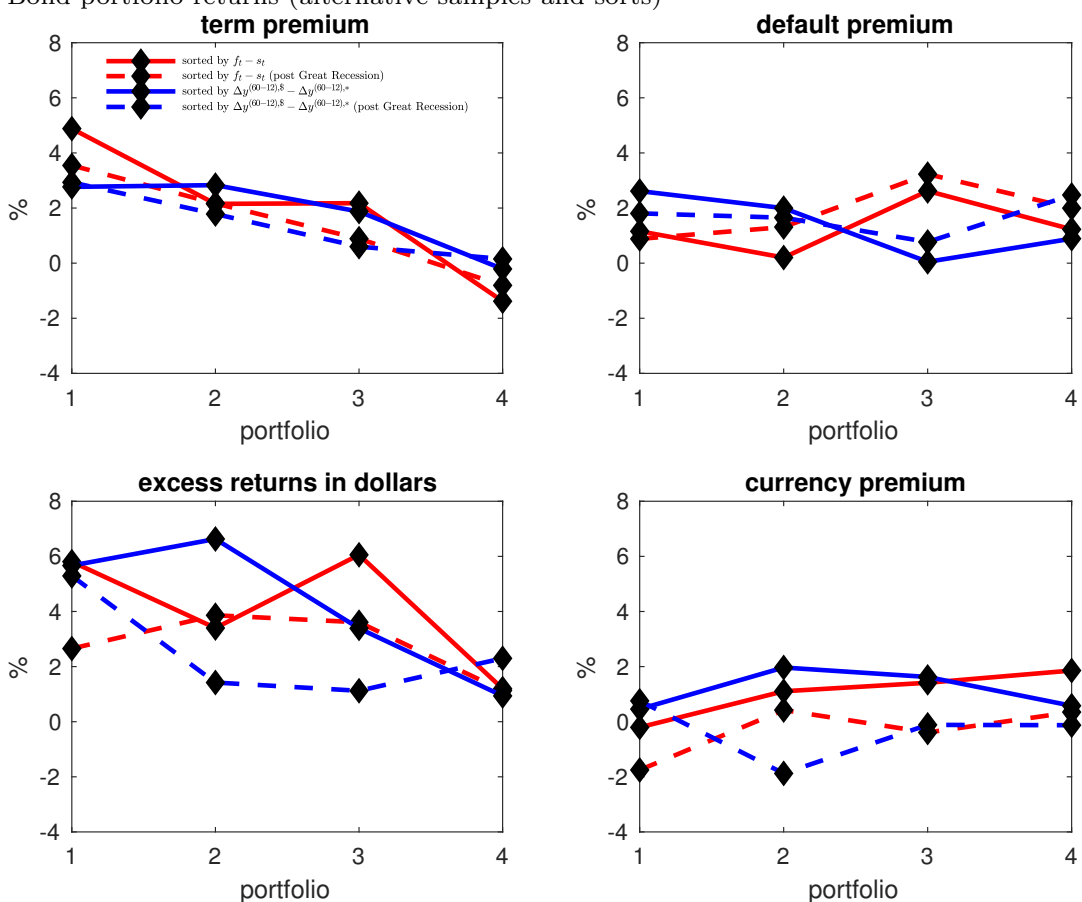

This figure plots the bond excess returns in dollars along with the term premium, the default premium, and the currency premium components described in Equation (1) for two different samples and two different sorts. The two sorts are by the short-term interest rates or by the yield curve slopes. The two samples are the benchmark sample from April 2005 to May 2019, or a shorter sample that starts after the U.S. Great Recession in July 2009. Returns are for bonds with a maturity of 60 months. Yield curve slopes are measured as the difference in the yields on zero-coupon bonds with maturity 60 and 12 months. Data are monthly and in percentages, from WM/Reuters and Bloomberg.

We assume that all countries share the same parameters $(\alpha, \chi, \gamma)$, but not $\delta$, that is the loading on the global shock $u^{w}$, and $\tau$, that is the loading on the global state $z_{t}^{w}$, which are the only two sources of heterogeneity in the parameters defining the SDFs in all countries. We omit the superscript $i$ when we refer to the United States which is characterized by the average $\delta$ and $\tau$.

We further assume that the same innovations that drive pricing kernel variations also govern the dynamics of the country-specific and world volatility processes that follow the following autoregressive square root 


$$
\text { "em port'final" — 2021/5/3 - 12:15 — page } 25 \text { — \#25 }
$$

Global Risk in Long-Term Sovereign Debt

processes

$$
\begin{aligned}
& z_{t+1}^{i}=(1-\phi) \theta+\phi z_{t}^{i}-\sigma \sqrt{z_{t}^{i}} u_{t+1}^{i} \\
& z_{t+1}^{w}=\left(1-\phi^{w}\right) \theta^{w}+\phi^{w} z_{t}^{w}-\sigma^{w} \sqrt{z_{t}^{w}} u_{t+1}^{w} .
\end{aligned}
$$

We start by considering currency risk. We assume that financial markets are complete, but that some frictions in the goods markets prevent perfect risk-sharing across countries. Therefore, similar to Backus et al. (2001) and Brandt et al. (2006), we define the change in the real exchange rate $\Delta q^{i}$ between the United States and country $i$ as

$$
\begin{aligned}
\Delta q_{t+1}^{i} & =\tilde{m}_{t+1}-\tilde{m}_{t+1}^{i} \\
& =\chi\left(z_{t}^{i}-z_{t}\right)+z_{t}^{w}\left(\tau^{i}-\tau\right)+\sqrt{\gamma z_{t}^{i}} u_{t+1}^{i}-\sqrt{\gamma z_{t}} u_{t+1} \\
& +u_{t+1}^{w} \sqrt{z_{t}^{w}}\left(\sqrt{\delta^{i}}-\sqrt{\delta}\right)
\end{aligned}
$$

where $q^{i}$ is measured in units of country $i$ goods per U.S. good. An increase in $q^{i}$ denotes a depreciation of the local currency with respect to the currency of foreign investors (i.e., U.S. investors). The exchange rate between country $i$ and the United States depends on country- $i$ and U.S.-specific shocks $\left(u_{t+1}^{i}, u_{t+1}\right)$, and on the global shock $\left(u_{t+1}^{w}\right)$. Note that, ceteris paribus, the exchange rate with respect to the United States responds differently to global shocks $u^{w}$ depending on the relative exposure captured by $\left(\sqrt{\delta^{i}}-\sqrt{\delta}\right)$. Specifically, the exchange rate of countries with relatively high (low) exposure to the global shock depreciates (appreciates) after a positive global shock (i.e., in good times), and appreciates (depreciates) after a negative global shock (i.e., in bad times). Differences in the loading on the global state, captured by $\left(\tau^{i}-\tau\right)$, and in the local states, captured by $\left(z_{t}^{i}-z_{t}\right)$, only affect the conditional mean of the changes in the exchange rate.

The second source of risk is that emerging market governments might inflate away their debt. In this scenario, the nominal exchange rate would eventually depreciate to accommodate this event. To investigate this possibility, we specify a process for the nominal SDF, in order to determine nominal variables, such as nominal interest rates and exchange rates. The log of the nominal SDF in country $i$ is simply given by the real SDF less the rate of inflation $\pi^{i}$ :

$$
m_{t+1}^{i}=\tilde{m}_{t+1}^{i}-\pi_{t+1}^{i}
$$

where we assume that inflation is time varying. In particular, we assume that it follows an autoregressive square root process similar to the one for the SDFs:

$$
\pi_{t+1}^{i}=\pi_{0}^{i}+\eta^{i} z_{t}^{i}+\eta^{w, i} z_{t}^{w}+\sigma_{\pi}^{i} \sqrt{z_{t}^{i}} u_{t+1}^{i}+\sigma_{\pi}^{w, i} \sqrt{z_{t}^{w}} u_{t+1}^{w} .
$$




$$
\text { "em port'final" — 2021/5/3 — 12:15 — page } 26 \text { - \#26 }
$$

Review of Asset Pricing Studies / v 00 n 02015

Note that inflation affects not only the conditional means but also the conditional variances and correlations of nominal variables. While in principle all parameters in (5) are country specific, we assume that all countries have the same parameters $\eta, \eta^{w}, \sigma_{\pi}, \sigma_{\pi}^{w}$, and that the United States and emerging countries differ only with respect to the parameter pinning down the unconditional mean, that is, $\pi_{0}$. Similarly to the real counterpart, the nominal exchange rate is defined as the difference between the nominal SDFs, which in turn is equal to the sum of the real exchange rate growth and the difference in inflation rates

$$
\Delta s_{t+1}^{i}=m_{t+1}-m_{t+1}^{i}=\Delta q_{t+1}^{i}+\left(\pi_{t+1}^{i}-\pi_{t+1}\right)
$$

The third source of risk is default risk. We assume that emerging markets issue risky zero-coupon bonds in local currency with maturity $m$. The one-period nominal return on investing in the risky bond of country $i$ is

$$
R_{t+1}^{(m), i}=\frac{\left(1-H_{t+1}^{i}\right)\left(P_{t+1}^{(m-1), i}\right)}{P_{t}^{(m), i}},
$$

where $P^{(m), i}$ is the nominal price of the zero-coupon bond maturing in $m$ periods, and $H^{i}$ captures the recovery in case of default and is the same for bonds of any maturity. For example, $H=0$ corresponds to no default, while $H=1$ to default with zero recovery. We further assume that the $\log$ recovery $h_{t}^{i}=\log \left(1-H_{t}^{i}\right)$ follows an exponentially affine process that is function of the country-specific and global states and shocks

$$
-h_{t}^{i}=\mu_{h}^{i}+\psi_{h}^{i} z_{t}^{i}+\psi_{h}^{w, i} z_{t}^{w}+\sigma_{h}^{i} \sqrt{z_{t}^{i}} u_{t+1}^{i}+\sigma_{h}^{w, i} \sqrt{z_{t}^{w}} u_{t+1}^{w} .
$$

Since in the data we do not observe a cross-section of the default premium, we assume that all emerging countries have the same parameters $\mu_{h}^{i}, \psi_{h}^{i}, \psi_{h}^{w, i}, \sigma_{h}^{i}, \sigma_{h}^{w, i}$, while bonds issued by the U.S. Treasury are default-free (i.e., $h_{t}=0$ for all $t$ ). After log-linearization, the nominal return of investing in the risky bond with maturity $m$ is

$$
r_{t+1}^{(m), i} \approx p_{t+1}^{(m-1), i}-p_{t}^{(m), i}+h_{t+1}^{i}
$$

and an increase in the default realization (i.e., a drop in $h$ ) is associated to a lower bond return. In this case, the process for the risky bond log price is affine

$$
p_{t}^{(m), i}=A^{(m), i}+B^{(m), i} z_{t}^{i}+C^{(m), i} z_{t}^{w},
$$

where the coefficients $A^{(m), i}, B^{(m), i}$, and $C^{(m), i}$ result from applying the equilibrium Euler equation to nominal bond returns in local currency

$$
\begin{aligned}
& \text { (i.e., } \left.E_{t}\left[M_{t+1}^{i} R_{t+1}^{(m), i}\right]=1\right) \\
& A^{(m), i}=A^{(m-1), i}-\left(\alpha+\pi_{0}^{i}+\mu_{h}\right)+B^{(m-1), i}(1-\phi) \theta+C^{(m-1), i}\left(1-\phi^{w}\right) \theta^{w} \\
& B^{(m), i}=B^{(m-1), i} \phi-\left(\chi+\eta+\psi_{h}\right)+0.5\left(\sqrt{\gamma}+\sigma_{\pi}+B^{(m-1), i} \sigma+\sigma_{h}\right)^{2} \\
& C^{(m), i}=C^{(m-1), i} \phi^{w}-\left(\tau+\eta^{w}+\psi_{h}^{w}\right)+0.5\left(\sqrt{\delta^{i}}+\sigma_{\pi}^{w}+C^{(m-1), i} \sigma^{w}+\sigma_{h}^{w}\right)^{2}
\end{aligned}
$$




$$
\text { "em port'final" — 2021/5/3 — 12:15 — page } 27 \text { — \#27 }
$$

Global Risk in Long-Term Sovereign Debt

and obtained using an iterative procedure starting with the coefficients for the one-period zero-coupon bond which are derived in closed form

$$
\begin{aligned}
& A^{(1), i}=-\mu_{h}-\alpha-\pi_{0}^{i} \\
& B^{(1), i}=-\left(\chi+\eta+\psi_{h}\right)+0.5\left(\sqrt{\gamma}+\sigma_{\pi}+\sigma_{h}\right)^{2} \\
& C^{(1), i}=-\left(\tau+\eta^{w}+\psi_{h}^{w}\right)+0.5\left(\sqrt{\delta^{i}}+\sigma_{\pi}^{w}+\sigma_{h}^{w}\right)^{2} .
\end{aligned}
$$

The coefficients $A^{(m), i}, B^{(m), i}$, and $C^{(m), i}$ are for nominal defaultable zero-coupon bonds in local currency with maturity $m$ issued by country $i$. To obtain the corresponding coefficients for nominal default-free zero-coupon bonds we simply need to set all the coefficients of the recovery process (7) in (10)-(12) to zero. We denote the default-free bond coefficients $A^{(m), i, f}, B^{(m), i, f}$, and $C^{(m), i, f}$.

We use Equations (8) and (9), and the coefficients for risky and default-free zero-coupon bonds, to derive expressions for all the components of the decomposition of excess bond returns in dollars described in (1).

The short-term interest rate differential is equal to

$$
\begin{aligned}
r_{t}^{(1), i, f}-r_{t}^{(1), \$, f} & =\left(\pi_{0}^{i}-\pi_{0}\right)+\left[0.5\left(\sqrt{\gamma}+\sigma_{\pi}\right)^{2}-(\chi+\eta)\right]\left(z_{t}-z_{t}^{i}\right) \\
& +\left[0.5\left(\sqrt{\delta}-\sqrt{\delta^{i}}\right)\left(\sqrt{\delta}+\sqrt{\delta^{i}}+2 \sigma_{\pi}^{w}\right)+\left(\tau^{i}-\tau\right)\right] z_{t}^{w}
\end{aligned}
$$

where $r_{t}^{(1), i, f}=-p_{t}^{(1), i, f}$ is the $\log$ risk-free rate. According to (13), emerging countries have a higher short-term risk-free rate than the United States the higher the average inflation rate $\left(\pi_{0}^{i}\right)$; the higher the loading on the global state $\left(\tau^{i}\right)$; and the lower the exposure to the global shock $\left(\delta^{i}\right)$. Differences in the local states can also potentially contribute to the short-term interest rate differential. We explore this possibility in Section H.II of the Internet Appendix.

The currency risk premium is equal to

$$
\begin{aligned}
E_{t}\left(r x_{t+1}^{F X, i}\right) & \equiv r_{t}^{(1), i, f}-r_{t}^{(1), \$, f}+E_{t}\left(\Delta s_{t+1}^{i}\right)= \\
& =0.5\left(\sqrt{\gamma}+\sigma_{\pi}\right)^{2}\left(z_{t}-z_{t}^{i}\right)+0.5 z_{t}^{w}\left(\sqrt{\delta}-\sqrt{\delta^{i}}\right)\left(\sqrt{\delta}+\sqrt{\delta^{i}}+2 \sigma_{\pi}^{w}\right),
\end{aligned}
$$

and, therefore, the conditional mean currency return provides compensation for the relative exposure to the global shock $\left(\delta^{i}\right)$, but does not depend on the different loadings on the global state $\left(\tau^{i}\right)$, because the latter is known at time $t$. Like in Lustig et al. (2011), the currency risk premium is positive for countries with a low $\delta^{i}$ with respect to the United States, that is for countries with high short-term risk-free rates. 


$$
\text { "em"port'final" — 2021/5/3 - 12:15 — page } 28 \text { — \#28 }
$$

Review of Asset Pricing Studies / v 00 n 02015

The (default-free) term premium with horizon $m$ is equal to

$$
\begin{aligned}
E_{t}\left(r_{t+1}^{(m, i, f)}-r_{t+1}^{(1, i, f)}\right) & =-z_{t}^{i}\left[B^{(m-1), i, f} \sigma\left(\sqrt{\gamma}+\sigma_{\pi}\right)+0.5\left(B^{(m-1), i, f} \sigma\right)^{2}\right]+ \\
& -z_{t}^{w}\left[C^{(m-1), i, f} \sigma^{w}\left(\sqrt{\delta^{i}}+\sigma_{\pi}^{w}\right)+0.5\left(C^{(m-1), i, f} \sigma^{w}\right)^{2}\right] .
\end{aligned}
$$

It is convenient to consider the term premium for infinite-maturity bonds, that is for $m \rightarrow \infty$, to understand the effect of the different parameters

$$
\begin{aligned}
E_{t}\left(r_{t+1}^{(\infty, i, f)}-r_{t+1}^{(1, i, f)}\right) & =z_{t}^{i}\left[0.5\left(\sqrt{\gamma}+\sigma_{\pi}\right)^{2}-(\chi+\eta)-B^{(\infty), i, f}(1-\phi)\right]+ \\
& +z_{t}^{w}\left[0.5\left(\sqrt{\delta^{i}}+\sigma_{\pi}^{w}\right)^{2}-\left(\tau^{i}+\eta^{w}\right)-C^{(\infty), i, f}\left(1-\phi^{w}\right)\right]
\end{aligned}
$$

where the coefficients $B^{(\infty), i, f}, C^{(\infty), i, f}$ are obtained implicitly in the second-order equations defined by (11) and (12). Following (15), we can see that the term premium directly increases in the exposure to the global shock, $\delta^{i}$, and decreases in the loading on the global state, $\tau^{i}$. Intuitively, since $\tau^{i}$ loads on the global state, it plays no role in shortterm currency returns, but it is important in bond returns, because it affects future prices through the pricing kernels at time $t+1, t+2, \ldots$. The term premium is indirectly affected by $\delta^{i}$ and $\tau^{i}$ through the coefficient $C^{(\infty), i, f}$, which is increasing in $\delta^{i}$ and decreasing in $\tau^{i}$ (for details, see Figure A9 in the Internet Appendix). The indirect effect of $\delta^{i}$ and $\tau^{i}$ through $C^{(\infty), i, f}$ partially offsets the direct effect of the two loadings on the term premium. Section 3.5 shows that we can match the documented increasing cross-section of currency premiums and decreasing cross-section of term premiums by parametrizing the model with a cross-section for $\delta^{i}$ and $\tau^{i}$.

Finally, the default premium with horizon $m$ is equal to

$$
\begin{aligned}
& E_{t}\left(r_{t+1}^{(\infty), i}-r_{t+1}^{(\infty), i, f}\right)= \\
& z_{t}^{i}\left[\left(B^{(\infty)}-B^{(\infty), f}\right)\left(B^{(\infty), f} \sigma^{2}-(1-\phi)\right)-\psi_{h}+B^{(\infty), f} \sigma \sigma_{h}\right]+ \\
& z_{t}^{w}\left[\left(C^{(\infty), i}-C^{(\infty), i, f}\right)\left(C^{(\infty), i, f}\left(\sigma^{w}\right)^{2}-\left(1-\phi^{w}\right)\right)-\psi_{h}^{w}+C^{(\infty), i, f} \sigma^{w} \sigma_{h}^{w}\right] .
\end{aligned}
$$

When the loadings of the default process (7) on the global state and global shock are zero (i.e., if $\left.\psi_{h}^{w}=0, \sigma_{h}^{w}=0\right)$, then $C^{(\infty), i}=C^{(\infty), i, f}$, and the default premium is independent of $z_{t}^{w}$. On the contrary, heterogeneity in the loadings on the global shock $\left(\delta^{i}\right)$ and global state $\left(\tau^{i}\right)$ could generate a cross-section of default premiums and, hence, contribute to bond excess returns. Finally, the volatility of the global shock of the default process $\left(\sigma_{h}^{w}\right)$ affects how heterogeneity influences the default premium. 


$$
\text { "em'port'final" — 2021/5/3 - 12:15 — page } 29 \text { — \#29 }
$$

Global Risk in Long-Term Sovereign Debt

\section{$3.2 \quad L M H$ portfolio returns}

We use the model to generate simulated data for bonds of different maturities and form portfolios based on short-term interest rates, as we have done in the data. While in Section 3.3 we discuss the model estimation and in Section 3.5 the model simulation, in this section, for the sake of illustration, we discuss the properties of $L M H$ portfolio returns for bonds with infinite maturity under the assumption that the local states $\left(z^{i}\right)$ are canceled out in portfolios. This assumption is useful to highlight the role of the heterogeneity with respect to the loadings on the global state and shock. In Section $\mathrm{H}$ of the Internet Appendix, we present the more general expressions, used in the estimation and simulation of the model, and also consider a special "symmetric" version of the model, where all countries have the same loadings on the global state and shock, to discuss the potential role of the local states (see Section H.II of the Internet Appendix). In the model simulation we show that differences in local states cannot quantitatively contribute to our results.

We use $L$ to denote the set of countries in the first portfolio and $H$ to denote the countries in the last portfolio. The source of differences in short-term interest rates is captured by the relative loading on the global shock, $\sqrt{\delta}-\sqrt{\delta^{i}}$, and by the relative loading on the global state, $\tau^{i}-\tau$. We assume that $\delta^{i}$ and $\tau^{i}$ are inversely related, that is countries with relatively high $\delta^{i}$ have relatively low $\tau^{i}$. We will show that this assumption is sufficient to replicate the stylized facts presented in Section 1. Given our assumption, the first (last) portfolio contains countries with low (high) short-term rates with respect to the United States, that is countries with high (low) $\delta^{i}$ and low (high) $\tau^{i}$.

To understand the effect of the loadings on the global shock and global state, we derive the conditional means of the $L M H$ portfolio returns for all the components of carry trade bond returns. We appeal to the law of large numbers and assume that the number of countries in each portfolio is large enough so that country-specific shocks average out to obtain closed-form expressions.

We start with the conditional $L M H$ currency premium, which is equal to

$$
E_{t}\left(L M H_{F X, t+1}\right)=0.5\left(\sqrt{\delta^{H}}-\sqrt{\delta^{L}}\right)\left(\sqrt{\delta^{H}}+\sqrt{\delta^{L}}+2 \sigma_{\pi}^{w}\right) z_{t}^{w},
$$

where $\delta^{j}$ with $j=L, H$ is the average $\delta^{i}$ across all countries in portfolio $j$. For portfolios sorted by short-term interest rates, the conditional mean in (17) is smaller or equal to zero because $\delta^{L} \geq \delta^{H}$.

The conditional $L M H$ term premium is equal to

$$
\begin{aligned}
& E_{t}\left(L M H_{T E R M}(\infty)_{, t+1}\right)=z_{t}^{w}\left[0.5\left(\sqrt{\delta^{L}}-\sqrt{\delta^{H}}\right)\left(\sqrt{\delta^{L}}+\sqrt{\delta^{H}}+2 \sigma_{\pi}^{w}\right)\right]+\ldots \\
& +z_{t}^{w}\left[\left(\tau^{H}-\tau^{L}\right)+\left(C^{(\infty), H, f}-C^{(\infty), L, f}\right)\left(1-\phi^{w}\right)\right],
\end{aligned}
$$

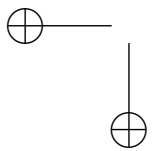




$$
\text { "em"port'final" — 2021/5/3 - 12:15 — page } 30 \text { — \#30 }
$$

Review of Asset Pricing Studies / v 00 n 02015

where $C^{(\infty), j, f}$ with $j=L, H$ is the average of the coefficients $C^{(\infty), i, f}$ across all countries in portfolio $j$. Contrary to the $L H M_{F X}$ premium, which depends only on the differences in the loading on the global shock $\delta$, the $L M H_{T E R M}$ premium directly increases in the relative loading on the global shock, and decreases in the relative loading on the global state. The $L M H_{T E R M}$ premium is further and indirectly affected by $\delta$ and $\tau$ through the term $C^{(\infty), H, f}-C^{(\infty), L, f}$, whose sign depends on the model parameters.

The conditional $L M H$ default premium is equal to

$$
\begin{aligned}
E_{t}\left(L M H_{D E F(\infty), t+1}\right) & =z_{t}^{w}\left(1-\phi^{w}\right)\left[C^{(\infty), H}-C^{(\infty), H, f}-C^{(\infty), L}+C^{(\infty), L, f}\right]+\ldots \\
& +z_{t}^{w}\left[\left(C^{(\infty), L}-C^{(\infty), H}\right) \sigma^{w} \sigma_{h}^{w}-\left(\sqrt{\delta^{L}}-\sqrt{\delta^{H}}\right) \sigma_{h}^{w}\right],
\end{aligned}
$$

where $C^{(\infty), j, f}$ and $C^{(\infty), j}$ with $j=L, H$ correspond, respectively, to the coefficients for the default-free and risky bonds.

Finally, the conditional $L M H$ carry trade risk premium is equal to the sum of (17)-(19):

$$
\begin{aligned}
& E_{t}\left(\operatorname{LMH}_{D O L_{t+1}^{(\infty)}}\right)=z_{t}^{w}\left[\left(\tau^{H}-\tau^{L}\right)+\left(C^{(\infty), H, f}-C^{(\infty), L, f}\right)\left(1-\phi^{w}\right)\right] \\
&+E_{t}\left(L M H_{D E F}(\infty), t+1\right. \\
&
\end{aligned}
$$

When $\tau^{i}$ is such that $C^{\infty, i, f}\left(\phi^{w}-1\right)=\tau^{i}+\eta^{w}$, then currency and term premiums offset each other, and the $L M H$ carry trade risk premium is simply equal to the $L M H$ default premium (see Equations (14) and (15)). Furthermore, if the default process in (7) does not load on the global state and the global shock (i.e., $\psi_{h}^{w}=0, \sigma^{w}=0$ ), then the $L M H$ dollar bond risk premium is equal to zero. A similar restriction is imposed by Lustig et al. (2019) to account for the fact that, for advanced economies with no default risk, carry trade returns with long-term bonds are not significantly different from zero.

Following the decomposition of the SDF in temporary $\left(m^{\mathbb{T}}\right)$ and permanent $\left(m^{\mathbb{P}}\right)$ components presented in Lustig et al. (2019), the restriction $C^{\infty, i, f}\left(\phi^{w}-1\right)=\tau^{i}+\eta^{w}$ implies that the permanent component of the SDF does not load on the global state:

$$
m_{t+1}^{i, \mathbb{P}} \equiv m_{t+1}^{i}-m_{t+1}^{i, \mathbb{T}}=-\log \beta-\left(\alpha+\pi_{0}\right)-(\chi+\eta) z_{t}-\left(\tau^{i}+\eta^{w}\right) \theta^{w}
$$

where the constant $\beta$ is chosen to satisfy some regularity condition established by Alvarez and Jermann (2005). ${ }^{5}$ For emerging market government bonds, sorted by interest rates or yield curve slopes, we

5 Alvarez and Jermann (2005) decompose the pricing kernel $\Lambda_{t}$ into a permanent component $\Lambda_{t}^{\mathbb{P}}$ and a transitory component $\Lambda_{t}^{\mathbb{T}}$ using the price of the long-term bond: $\Lambda_{t}=\Lambda_{t}^{\mathbb{P}} \Lambda_{t}^{\mathbb{T}}$, where $\Lambda_{t}^{\mathbb{T}}=\lim _{k \rightarrow \infty} \delta^{t+k} / P_{t}^{(k)}$, and $\delta$ is chosen to satisfy $0<\lim _{k \rightarrow \infty} P_{t}^{(k)} / \delta^{k}<\infty$ for all $t$. The $\log \mathrm{SDF}$ is $m_{t+1}=\Lambda_{t+1}-\Lambda_{t}$, and $m_{t+1}=m_{t+1}^{\mathbb{P}}+m_{t+1}^{\mathbb{T}}$.

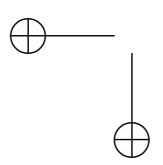




$$
\text { "em port'final" — 2021/5/3 — 12:15 — page } 31 \text { — \#31 }
$$

Global Risk in Long-Term Sovereign Debt

documented a declining cross-section of the term premium and an increasing cross-section of the currency premium that do not offset each other. For the model to account for these empirical findings, one solution is to assume that countries differ along two dimensions: the loading on the global shock $\left(\delta^{i}\right)$ and the loading on the global state $\left(\tau^{i}\right)$. In this case, the permanent component of the SDF loads differentially on the global state and

$$
L_{t}\left(m_{t+1}^{\mathbb{P}, H}\right) \geq L_{t}\left(m_{t+1}^{\mathbb{P}, L}\right),
$$

where $L(X)$ denotes the entropy of variable $X^{6}$. In other words, the entropy of the permanent component of the domestic SDF for countries in the first portfolio (low short-term interest rates) must be smaller than for countries in the last portfolio (high short-term interest rate).

The model has enough flexibility to reproduce the cross-section of the currency premium and term premium with alternative assumptions. One possibility, is the introduction of heterogeneity in the inflation process. If $\tau^{i}+\eta^{w}=\tau+\eta^{w, i}$ and $\sqrt{\delta^{i}}+\sigma_{\pi}^{w}=\sqrt{\delta}+\sigma_{\pi}^{w, i}$, then we can obtain the same cross-section of nominal variables, such as the short-term interest rate differential, the exchange rate growth, and the currency and term premiums. However, with this specification, real variables would be identical across countries and we could not obtain a cross-section of real short-term interest rates.

A further possibility is the introduction of heterogeneity in the default process $h^{i}$. With this specification, we could obtain the same crosssection of bond excess returns in dollars, as the default process enters additively in (8) and, consequently, influences the coefficient associated to the loading of the risky bond on the global state (12) similarly to the processes for the SDF and inflation. However, this parametrization would not affect on the exchange rate growth, the (default-free) term premium, or the short-term interest rate differential.

\subsection{Estimation}

In this section, we estimate the model on a sample of moments and compare its predictions to the data for the United States and the set of emerging markets for the period April 2005 to May 2019.

The estimation procedure follows Lustig et al. (2014) and is based on a version of the GMM estimator that targets 19 annualized moments of monthly data for the United States and the emerging markets in our sample. We impose a set of restrictions to reduce the number of model parameters to 18 (see Section H.V in the Internet Appendix for

6 The conditional entropy $L_{t}$ of a random variable $X_{t+1}$ is defined as $L_{t}\left(X_{t+1}\right)=$ $\log E_{t}\left(X_{t+1}\right)-E_{t}\left(\log X_{t+1}\right)$. If $X_{t+1}$ is conditionally normally distributed, then $L_{t}\left(X_{t+1}\right)=(1 / 2) \operatorname{var}_{t}\left(\log X_{t+1}\right)$. See Section $H$ in the Internet Appendix for a proof of (21).

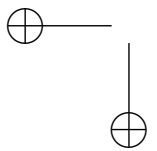




$$
\text { "em"port'final" — 2021/5/3 - 12:15 — page } 32 \text { — \#32 }
$$

Review of Asset Pricing Studies / v 00 n 02015

further details). We assume that the local and global states follow the same process and that the loadings on the local state variable for the inflation and recovery processes are zero. The latter is not a crucial assumption because, by building portfolios, we average out the local components. While the target moments associated to the real interest rate, exchange rate, inflation rate, and default process have all closedform expressions, the target moments associated to the term premium, default premium, and carry trade premium are obtained iteratively following the procedure described in Sections 3.1-3.2.

The GMM objective function minimizes a weighted sum of the squared differences between closed-form expressions for these moments and their empirical counterparts. We provide standard errors for both the sample moments and the moments implied by the estimated parameter values. These standard errors are computed using a stationary block-bootstrap procedure with varying block-length and 1,000 bootstraps. While Table 4 presents all the moments and the corresponding target and simulated values, Table 5 illustrates all the estimated parameter values used in the simulation.

Even though we estimate all parameters jointly, for expositional purposes, we group parameters and targets corresponding to different parts of the model: real variables; inflation rates; default risk; and heterogeneity. In what follows, the average emerging country is characterized by the average exposure to the global shock and average loading on the global state.

3.3.1 Real variables. We first focus on the real moments, and assume that the two state variables share the same parameters (i.e., $\left.\phi=\phi^{w}, \theta=\theta^{w}, \sigma=\sigma^{w}\right)$. Five parameters govern the dynamics of the real SDFs $\left(\alpha, \chi, \gamma, \tau^{\star}, \delta^{\star}\right)$, and three parameters govern the dynamics of the two state variables $(\phi, \theta, \sigma)$. We assume that the parameters $\delta$ and $\tau$ for the United States are the same as for the average emerging country. We choose eight target moments associated to real variables: the crosssectional mean of the U.I.P. slope coefficients; the unconditional mean, the unconditional standard deviation and the persistence of the U.S. risk-free rate; the cross-sectional mean of the volatility of the changes in the exchange rate; the maximum Sharpe ratio (i.e., the standard deviation of the log SDF); the unconditional carry trade risk premiums; and a Feller parameter to satisfy an important regularity condition to avoid that the $z$ and $z^{w}$ processes are negative. Panel A of Table 4 reports these moments and targets. ${ }^{7}$

7 A square root process has the property that will always remain nonnegative in continuous time (see, e.g., Campbell (2018), chap. 8.3). In discrete time, it takes negative values with positive probability at every step. If the Feller condition $2(1-\phi) \theta / \sigma^{2}>1$ is satisfied, then 


$$
\text { "em port'final" — 2021/5/3 — 12:15 — page } 33 \text { — \#33 }
$$

Global Risk in Long-Term Sovereign Debt

3.3.2 Inflation. We assume that the only difference in the inflation process for the U.S. and emerging markets is that the former has a lower average inflation. We further assume that emerging markets do not differ in terms of the inflation process; and fix the loading on the local state $(\eta)$ to zero. We are left with five parameters $\left(\pi_{0}^{U S}, \pi_{0}^{E M}, \eta^{w}, \sigma_{\pi}, \sigma_{\pi}^{w}\right)$ that characterize the inflation process (5). We choose six target moments associated to inflation: the mean inflation rate in the U.S. and emerging markets; the standard deviation of the inflation rate and fraction of inflation explained by the global shock for the emerging markets in our sample and the mean term premium for the average emerging country. Panel B of Table 4 reports these moments and targets.

3.3.3 Default. We assume that the recovery process is independent on the and local state and, therefore, $\psi_{h}=0$. We are left with four parameters of the recovery process. We choose the following targets associated to the default: the mean and volatility of the historical default probabilities (for details, see Section B in the Internet Appendix) and the $L M H$ default premium, whose cross-section depends on the value of $\sigma_{h}^{w}$. Panel $\mathrm{C}$ of Table 4 reports these moments and targets.

3.3.4 Cross-sectional Heterogeneity. We assume two sources of heterogeneity for emerging markets: the first is the loading on the global shock $(\underline{\delta}, \bar{\delta})$; the second is the loading on the global state $(\underline{\tau}, \bar{\tau})$. For the U.S. and the average emerging market, we assume $\delta^{\star}=(1 / 2)(\underline{\delta}+$ $\bar{\delta})$, and $\tau^{\star}=(1 / 2)(\underline{\tau}+\bar{\tau})$. Recall that we assume that $\delta^{i}$ and $\tau^{i}$ are inversely related (i.e., the county with the lowest $\underline{\delta}$ has the highest $\bar{\tau})$. We choose the following targets associated to the cross-sectional heterogeneity: the mean $L M H$ term premium and $L M H$ currency premium. Differences in $\delta^{i}$ are responsible for the cross-section of $L M H$ currency premiums (as in, e.g., Lustig et al. (2011)), while differences in $\tau^{i}$ are responsible for the cross-section of $L M H$ term premiums. Panel D of Table 4 reports these moments and targets. One way to think about the economic interpretation of the different values of $\delta$ and $\tau$ is in terms of their effect on the short-term risk-free rate (i.e., recall that $\left.r_{t}^{f}=-E_{t}\left(m_{t+1}\right)-(1 / 2) \sigma_{t}^{2}\left(m_{t+1}\right)\right)$. In this respect, $\tau$ is related to the elasticity of intertemporal substitution (EIS), while $\delta$ to the precautionary saving effect. More specifically, countries with higher $\tau$ and lower $\delta$ are characterized by a lower EIS and a lower precautionary saving effect.

there exists a unique positive solution to the Equation defining the volatility processes $\mathrm{z}$ in the continuos-time limit (Feller, 1951). A Feller coefficient of at least 20 (our target value) guarantees that, in our simulations, all the state variables following square root processes are positive (see, e.g., Lustig et al. (2011)). Results are robust to the introduction of an inequality constraint, such as Feller $\geq 20$. 


$$
\text { "em"port'final" — 2021/5/3 - 12:15 — page } 34 \text { — \#34 }
$$

Review of Asset Pricing Studies / v 00 n 02015

Table 5 reports the estimated parameter values along their standard errors. As in Lustig et al. (2014), the parameters are not estimated very precisely. In this respect, we first note the fact that also the target moments are estimated with large standard errors by the bootstrap procedure. Second, the documented evidence of a significant crosssection of carry trade, term, and currency premiums clearly indicates that the loadings $\delta$ and $\tau$ cannot be equal to zero. To support this observation, in Section 3.5 we use the simulated model to study the properties of carry trade returns in simulated data.

\subsection{Model fit}

Panel E in Table 4 reports some additional moments that were not used in the estimation. The model very closely matches the unconditional mean dollar excess returns $(0.40 \%$ vs $0.32 \%)$, the $L M H$ dollar returns $(0.32 \%$ vs. $0.37 \%)$, the $L M H$ term premium returns for bonds with a maturity of 10 years $(0.56 \%$ vs. $0.55 \%)$, and the unconditional mean yield for the benchmark maturity of 5 years for emerging markets $(0.64 \%$ vs. $0.52 \%)$ and the United States (0.50\% vs. $0.25 \%)$, although the latter two moments are matched with a large standard error.

\subsection{Simulation}

We use the estimated parameters in Table 5 to simulate the model. First, we draw 100,000 observations of the shocks and generate simulated data for the U.S. and 30 emerging markets. Second, we use the simulated data to compute the prices and corresponding returns of zero-coupon bonds with maturities from 1 to 120 months. Third, we form five portfolios sorting the simulated countries by the short-term interest, as we did in Section 1.

Table 6 illustrates the properties of the five portfolios, and of the $L M H$ (i.e., 1-5) portfolios ${ }^{8}$. Recall that the $L M H$ investment strategy goes long in the first portfolio, containing low short-term interest rate countries (i.e., high $\delta^{i}$ and low $\tau^{i}$ ), and goes short in the last portfolio, containing high short-term interest rate countries (i.e., low $\delta^{i}$ and $\tau^{i}$ ). The model reproduces the declining cross-section for the term premium; the increasing cross-section for the currency premium, and the flat positive small default premium, which we documented in our sample of emerging markets. Bond excess returns in dollars are positive for all portfolios; decline from $4.84 \%$ on the first portfolio to $0.35 \%$ on the last portfolio, and are driven by the large term premium. Note that bond excess returns in dollars are positive also for the last portfolio,

8 Our simulation results are robust to a different number of countries and/or portfolios provided that country-specific shocks are averaged out in portfolios. 
characterized by a very small term premium, because of the positive contribution of the default premium.

We summarize our simulation results in Figure 6, which plots the mean $L M H$ term premium, $L M H$ default premium, and bond excess returns in dollars as function of bond maturity. The $L M H$ term premium is positively sloped and increases from 0 to $5.90 \%$ per annum at a maturity of 60 months. The $L M H$ default premium is flat and approximately equal to $-0.12 \%$. Finally, the $L M H$ currency premium is equal to approximately $-1.25 \%$ per annum. The $L M H$ bond excess return in dollars is, then, also positively sloped: it increase from $-1.1 \%$ at maturity of 1 month to $4.5 \%$ at a maturity of 60 months.

Figure 6

Simulated low-minus-high bond returns
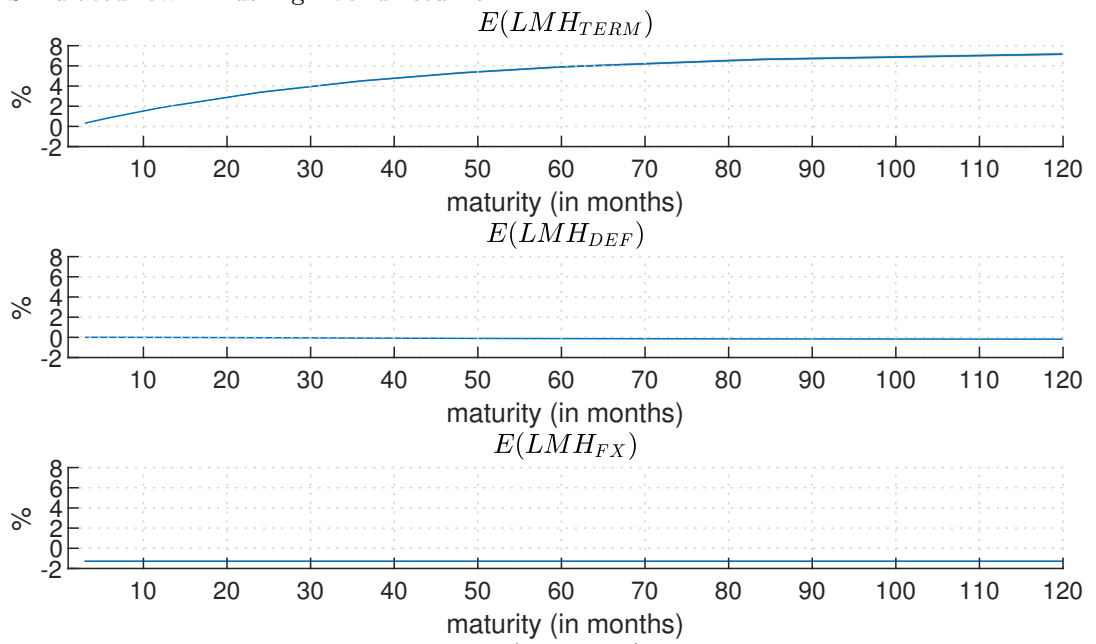
$E\left(L M H_{D O L}\right)$

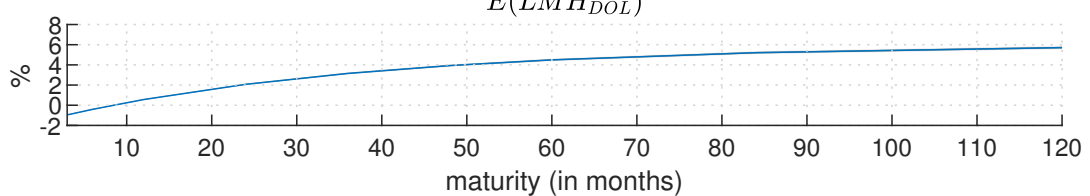

This figure uses model simulated data to plot the $L M H$ bond returns in dollars, the term premium, and the default premium for different maturities. $L H M$ returns correspond to a strategy that goes long in portfolio 1 and short in portfolio 4 . Portfolios are formed by sorting countries by their short-term interest rate differential with respect to the United States. The holding period for returns is 1 month and returns are annualized. The darkshaded area corresponds to one-standard-error bands around the point estimates; the light-gray-shaded area corresponds to $95 \%$ confidence intervals. Standard errors are by bootstrap. Simulation parameter values are reported in Table 5. 


$$
\text { "em"port'final" — 2021/5/3 - 12:15 — page } 36 \text { - \#36 }
$$

Review of Asset Pricing Studies / v 00 n 02015

\section{Conclusion}

In this paper, we study emerging market government bond returns in local currency from the perspective of foreign investors. The main risks to investors are interest rate, currency, and credit risks. We allocate countries to portfolios sorted by short-term interest rates or yield curve slopes, two strong predictors of currency and bond returns, and consider the entire term structure of carry trade bond returns. For maturities longer than one year, both strategies produce a large and declining crosssection of term premiums that more than offsets an increasing crosssection of currency premiums. The default premium is similar across countries and does not contribute to carry trade returns.

We introduce default risk in an otherwise standard affine term structure model and show that the volatility of the permanent component of the SDFs must be different across emerging markets in order to match these stylized facts. By sorting countries by shortterm interest rates, which is the main sorting variable in the currency literature, we obtain not only a cross-section of currency premiums, but also of term premiums. This indicates the connection between currency and term structure of bond risk premiums. To replicate the positive carry trade returns with long-term bonds, the volatility of permanent shocks to the SDFs of emerging markets with low short-term interest rate must be lower than for emerging markets with high short-term interest rates. To the best of our knowledge, this is a new and important result for emerging markets, in part related to Aguiar and Gopinath (2007), which argues that shocks to trend growth are the primary source of fluctuations in emerging markets.

We consider our results as a first step in understanding the different components of the cross-section of emerging market government bonds returns in local currencies. We leave for future research the analysis of the liquidity of these bonds, which is a potential additional component of the term structure of bond returns. As suggested in Du and Schreger (2016), in good times, the market for local currency government bonds is relatively liquid. However, in bad times, higher bid/ask spreads and reversal in foreign flows could increase the role of the liquidity component. 


$$
\text { "em port'final" — 2021/5/3 — 12:15 — page } 37 \text { — \#37 }
$$

Global Risk in Long-Term Sovereign Debt

References
Adrian, T., R. K. Crump, and E. Moench. 2013. Pricing the term structure with linear regressions.

Aguiar, M., S. Chatterjee, H. Cole, and Z. Stangebye. 2016. Quantitative Models of Sovereign Debt Crises. Handbook of Macroeconomics 2:1697-1755.

Aguiar, M., and G. Gopinath. 2007. Emerging market business cycles: The cycle is the trend. Journal of Political Economy 115:69-102.

Akram, Q. F., D. Rime, and L. Sarno. 2008. Arbitrage in the foreign exchange market: Turning on the microscope. Journal of International Economics 76:237-253.

Alvarez, F., and U. J. Jermann. 2005. Using asset prices to measure the persistence of the marginal utility of wealth. Econometrica 73:1977-2016.

Andrews, D. W. 1991. Heteroskedasticity and autocorrelation consistent covariance matrix estimation. Econometrica: Journal of the Econometric Society pp. 817-858.

Ang, A., and F. A. Longstaff. 2013. Systemic sovereign credit risk: Lessons from the US and Europe. Journal of Monetary Economics 60:493-510.

Arslanalp, M. S., and M. T. Tsuda. 2014. Tracking global demand for emerging market sovereign debt. 14-39. International Monetary Fund.

Backus, D., N. Boyarchenko, and M. Chernov. 2018. Term structures of asset prices and returns. Journal of Financial Economics 129:1-23.

Backus, D. K., S. Foresi, and C. I. Telmer. 2001. Affine term structure models and the forward premium anomaly. The Journal of Finance 56:279-304.

Backus, D. K., F. Gavazzoni, C. Telmer, and S. E. Zin. 2010. Monetary policy and the uncovered interest parity puzzle. Tech. rep., National Bureau of Economic Research.

Bansal, R., and M. Dahlquist. 2000. The forward premium puzzle: different tales from developed and emerging economies. Journal of International Economics 51:115-144.

Bansal, R., and B. N. Lehmann. 1997. Growth-optimal portfolio restrictions on asset pricing models. Macroeconomic dynamics 1:333-354.

Borri, N. 2018. Local currency systemic risk. Emerging Markets Review 34:111-123.

Borri, N., and A. Verdelhan. 2011. Sovereign risk premia.

Brandt, M. W., J. H. Cochrane, and P. Santa-Clara. 2006. International risk sharing is better than you think, or exchange rates are too smooth. Journal of Monetary Economics 53:671-698.

Buraschi, A., M. Menguturk, and E. Sener. 2014. The Geography of Funding Markets and Limits to Arbitrage. The Review of Financial Studies 28:1103-1152.

Calvo, G. A., and C. M. Reinhart. 2002. Fear of floating. The Quarterly Journal of Economics 117:379-408

Campbell, J. Y. 2018. Financial decisions and markets: a course in asset pricing. Princeton University Press.

Cochrane, J. H. 2009. Asset Pricing:(Revised Edition). Princeton university press.

Cochrane, J. H., and M. Piazzesi. 2005. Bond risk premia. American Economic Review 95:138-160.

Colacito, R., M. M. M. Croce, F. Gavazzoni, and R. Ready. 2018. Currency risk factors in a recursive multicountry economy . 


$$
\text { "em port'final" — 2021/5/3 — 12:15 — page } 38 \text { — \#38 }
$$

Review of Asset Pricing Studies / v 00 n 02015

Cruces, J. J., and C. Trebesch. 2013. Sovereign Defaults: The Price of Haircuts. American Economic Journal: Macroeconomics 5:85-117.

Crump, R. K., and N. Gospodinov. 2019. Deconstructing the yield curve. FRB of New York Staff Report.

Della Corte, P., S. J. Riddiough, and L. Sarno. 2016. Currency premia and global imbalances. The Review of Financial Studies 29:2161-2193.

Dew-Becker, I., S. Giglio, A. Le, and M. Rodriguez. 2017. The price of variance risk. Journal of Financial Economics 123:225-250.

Du, W., J. Im, and J. Schreger. 2018a. The US treasury premium. Journal of International Economics 112:167-181.

Du, W., and J. Schreger. 2016. Local currency sovereign risk. The Journal of Finance .

Du, W., A. Tepper, and A. Verdelhan. 2018b. Deviations from covered interest rate parity. The Journal of Finance 73:915-957.

Duffie, D., L. H. Pedersen, and K. J. Singleton. 2003. Modeling sovereign yield spreads: A case study of Russian debt. The Journal of Finance 58:119-159.

Eichengreen, B., R. Hausmann, and U. Panizza. 2003. The pain of original sin. Other people's money: Debt denomination and financial instability in emerging market economies pp. 1-49.

Fama, E. F., and K. R. French. 1993. Common risk factors in the returns on stocks and bonds. Journal of Financial Economics 33:3-56.

Fama, E. F., and J. D. MacBeth. 1973. Risk, return, and equilibrium: Empirical tests. Journal of Political Economy 81:607-636.

Farhi, E., S. P. Fraiberger, X. Gabaix, R. Ranciere, and A. Verdelhan. 2009. Crash risk in currency markets. Tech. rep., National Bureau of Economic Research.

Feller, W. 1951. Two singular diffusion problems. Annals of mathematics pp. 173-182.

Giglio, S., M. Maggiori, and J. Stroebel. 2014. Very long-run discount rates. The Quarterly Journal of Economics 130:1-53.

Goliński, A., and P. Spencer. 2017. The advantages of using excess returns to model the term structure. Journal of Financial Economics 125:163-181.

Guibaud, S., Y. Nosbusch, and D. Vayanos. 2013. Bond market clienteles, the yield curve, and the optimal maturity structure of government debt. The Review of Financial Studies 26:1914-1961

Hansen, L. P. 1982. Large sample properties of generalized method of moments estimators. Econometrica: Journal of the Econometric Society pp. 1029-1054.

Hansen, L. P., and J. A. Scheinkman. 2009. Long-term risk: An operator approach. Econometrica $77: 177-234$

Hassan, T. A. 2013. Country size, currency unions, and international asset returns. The Journal of Finance 68:2269-2308.

Hassan, T. A., and R. C. Mano. 2014. Forward and spot exchange rates in a multi-currency world. Tech. rep., National Bureau of Economic Research.

Ivashina, V., D. S. Scharfstein, and J. C. Stein. 2015. Dollar funding and the lending behavior of global banks. The Quarterly Journal of Economics 130:1241-1281.

Kealhofer, S. 2003. Quantifying credit risk I: default prediction. Financial Analysts Journal pp. 30-44. 


$$
\text { "em port'final" — 2021/5/3 — 12:15 — page } 39 \text { — \#39 }
$$

Global Risk in Long-Term Sovereign Debt

Krishnamurthy, A., and A. Vissing-Jorgensen. 2012. The aggregate demand for treasury debt. Journal of Political Economy 120:233-267.

Lettau, M., M. Maggiori, and M. Weber. 2014. Conditional risk premia in currency markets and other asset classes. Journal of Financial Economics 114:197-225.

Lewellen, J., S. Nagel, and J. Shanken. 2010. A skeptical appraisal of asset pricing tests. Journal of Financial Economics 96:175-194.

Liao, G. Y. 2020. Credit migration and covered interest rate parity. Journal of Financial Economics .

Litterman, R., and J. Scheinkman. 1991. Common factors affecting bond returns. Journal of Fixed Income 1:54-61.

Longstaff, F. A., J. Pan, L. H. Pedersen, and K. J. Singleton. 2011. How sovereign is sovereign credit risk? American Economic Journal: Macroeconomics 3:75-103.

Lustig, H., N. Roussanov, and A. Verdelhan. 2011. Common risk factors in currency markets. The Review of Financial Studies 24:3731-3777.

Lustig, H., N. Roussanov, and A. Verdelhan. 2014. Countercyclical currency risk premia. Journal of Financial Economics 111:527-553.

Lustig, H., A. Stathopoulos, and A. Verdelhan. 2019. The term structure of currency carry trade risk premia. American Economic Review 109.

Mendoza, E. G. 2010. Sudden stops, financial crises, and leverage. American Economic Review 100:1941-66.

Na, S., S. Schmitt-Grohé, M. Uribe, and V. Yue. 2018. The twin ds: Optimal default and devaluation. American Economic Review 108:1773-1819.

Newey, W. K., K. D. West, et al. 1987. A Simple, Positive Semi-definite, Heteroskedasticity and Autocorrelation Consistent Covariance Matrix. Econometrica 55:703-708.

Paczos, W., and K. Shakhnov. 2016. Sovereign Debt Issuance and Selective Default. European University Institute Working Paper.

Ready, R., N. Roussanov, and C. Ward. 2017. Commodity trade and the carry trade: A tale of two countries. The Journal of Finance 72:2629-2684.

Reinhart, C. M., and K. S. Rogoff. 2011a. The Forgotten History of Domestic Debt. Economic Journal 121:319-350.

Reinhart, C. M., and K. S. Rogoff. 2011b. From Financial Crash to Debt Crisis. American Economic Review 101:1676-1706. Accessed online: June, 30, 2015.

Ross, S. A. 1976. The arbitrage theory of capital asset pricing. Journal of Economic Theory 13:341-360.

Sandulescu, M., F. Trojani, and A. Vedolin. 2018. Model-free international stochastic discount factors .

Shanken, J. 1992. On the estimation of beta-pricing models. The Review of Financial Studies 5:1-33.

Sturzenegger, F., and J. Zettelmeyer. 2008. Haircuts: estimating investor losses in sovereign debt restructurings, 1998-2005. Journal of International Money and Finance $27: 780-805$.

Valchev, R. 2020. Bond convenience yields and exchange rate dynamics. American Economic Journal: Macroeconomics 12:124-66. 
$\bigoplus$

$$
\text { "em"port'final" — 2021/5/3 — 12:15 — page } 40 \text { — \#40 }
$$

Review of Asset Pricing Studies / v 00 n 02015

Van Binsbergen, J. H., M. W. Brandt, and R. S. Koijen. 2012. Decentralized decision making in investment management. In The Oxford Handbook of Quantitative Asset Management, pp. 157-76. Univ. Press Oxford.

Verdelhan, A. 2014. The share of systematic variation in bilateral exchange rates. MIT Sloan Working Paper. 


$$
\text { "em port"final" — 2021/5/3 — 12:15 — page } 41 \text { — \#41 }
$$

Global Risk in Long-Term Sovereign Debt

Table 3

Characteristics of the bond portfolios

\begin{tabular}{|c|c|c|c|c|}
\hline Portfolio & 1 & 2 & 3 & 4 \\
\hline & \multicolumn{4}{|c|}{ Share foreign investors } \\
\hline Mean & 37.04 & 40.13 & 40.69 & 42.41 \\
\hline \multirow[t]{2}{*}{$S E$} & 0.80 & 0.93 & 0.88 & 0.68 \\
\hline & \multicolumn{4}{|c|}{ Inflation } \\
\hline Mean & 2.45 & 3.15 & 4.18 & 6.20 \\
\hline \multirow[t]{2}{*}{$S E$} & 0.14 & 0.15 & 0.12 & 0.11 \\
\hline & \multicolumn{4}{|c|}{ Default probabilities } \\
\hline Mean & 0.18 & 0.20 & 0.26 & 0.37 \\
\hline \multirow[t]{2}{*}{$S E$} & 0.01 & 0.01 & 0.01 & 0.01 \\
\hline & \multicolumn{4}{|c|}{ Debt-to-GDP } \\
\hline Mean & 37.31 & 40.37 & 41.01 & 42.64 \\
\hline \multirow[t]{2}{*}{$S E$} & 0.81 & 0.92 & 0.87 & 0.63 \\
\hline & \multicolumn{4}{|c|}{ Commodity EX share } \\
\hline Mean & 23.01 & 25.56 & 29.59 & 26.20 \\
\hline \multirow[t]{2}{*}{$S E$} & 1.13 & 1.04 & 0.96 & 0.80 \\
\hline & \multicolumn{4}{|c|}{ Commodity EX share (w/agriculture) } \\
\hline Mean & 37.00 & 40.04 & 45.38 & 42.61 \\
\hline \multirow[t]{2}{*}{$S E$} & 1.19 & 1.18 & 1.28 & 1.09 \\
\hline & \multicolumn{4}{|c|}{ Portfolio turnover } \\
\hline Mean & 42.86 & 56.45 & 56.99 & 29.90 \\
\hline$S E$ & 1.85 & 1.90 & 2.05 & 1.33 \\
\hline $\begin{array}{l}\text { is table reports, } \\
\text { res of local curr } \\
\text { babilities with } \\
\text { total exports e? } \\
\text { estimate defau } \\
\text { ereign bonds an } \\
\text { YoY changes o } \\
\text { the average num } \\
\text { m WM/Reuters, } \\
\text { Tsuda (2014). } \\
\text { Tort shares are a }\end{array}$ & $\begin{array}{l}\text { ch portfol } \\
\text { bonds he } \\
\text { r horizon; } \\
\text { ing and it } \\
\text { babilities } \\
\text { transition } \\
\text { CPI indes } \\
\text { f countries } \\
\text { mberg, S\& } \\
\text { data are }\end{array}$ & $\begin{array}{l}\text { the averag } \\
\text { foreign ii } \\
\text { total deb } \\
\text { ing agricu } \\
\text { S\&P cre } \\
\text { Sability m } \\
\text { nd in perc } \\
\text { change p } \\
\text { MF-IFS, V } \\
\text { a local so }\end{array}$ & $\begin{array}{l}\text { Ad bootstr } \\
\text { ors; the in } \\
\text { GDP rati } \\
\text { products } \\
\text { atings for } \\
\text { of Kealho } \\
\text { ges; portf } \\
\text { lio every 1 } \\
\text { Statistics } \\
\text { through }\end{array}$ & $\begin{array}{l}\text { Jard errors for the } \\
\text { rates; the default } \\
\text { commodity share } \\
\text { ortfolio turnover. } \\
\text { arrency long-term } \\
\text { 3); inflation rates } \\
\text { hover is measured } \\
\text { Data are monthly, } \\
\text { ise, and Arslanalp } \\
\text { eam. Commodity } \\
\text { riod is April } 2005\end{array}$ \\
\hline
\end{tabular}


Table 4

Model estimation

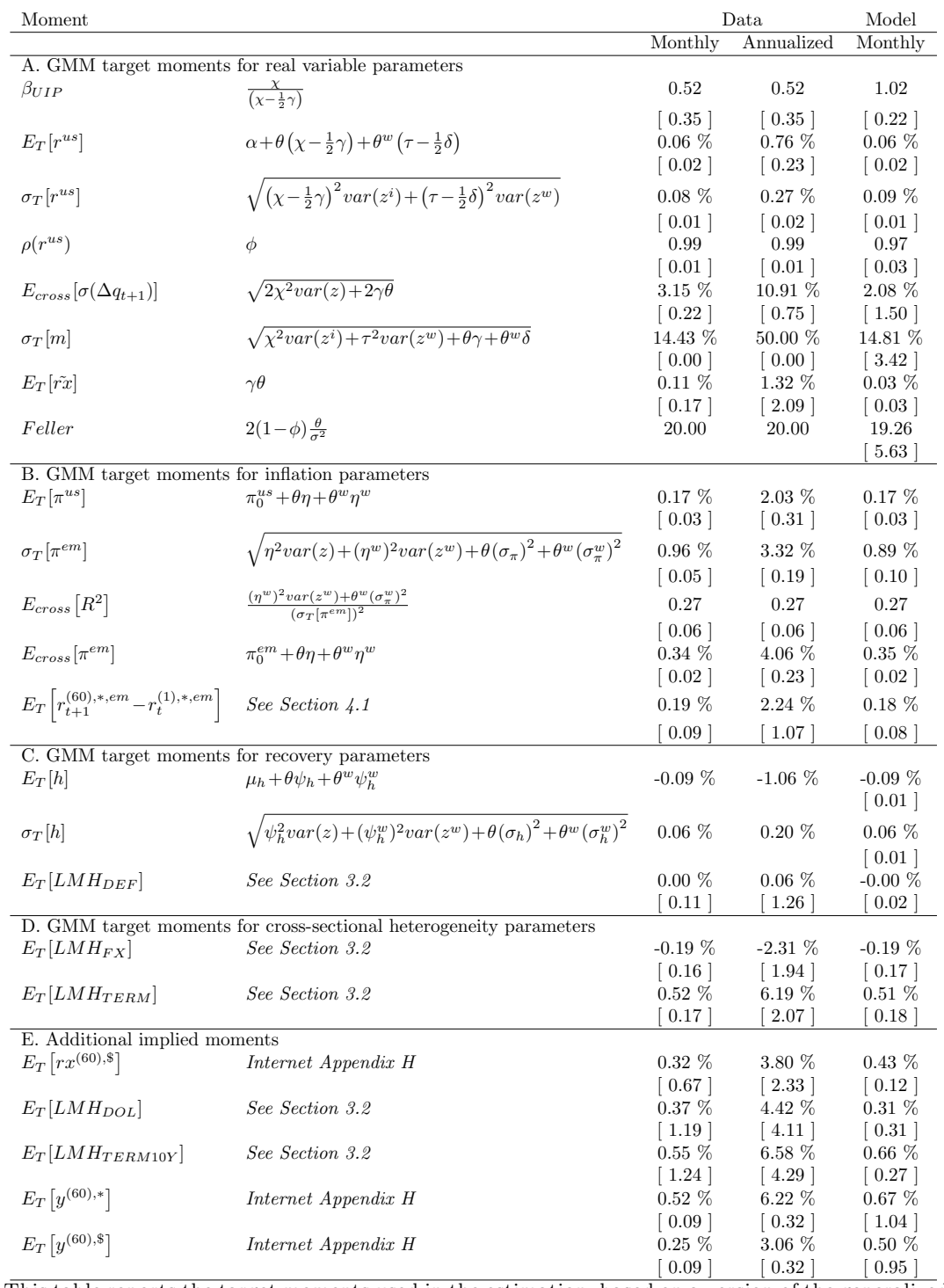

This table reports the target moments used in the estimation, based on a version of the generalize method of moments (GMM) estimator, and the corresponding simulated moments. All parameters are estimated jointly. The first column defines each moment, the second column presents its closedform expression. When a compact closed-form expression is not available, we refer to Sections 3.1 and 3.2 or the Internet Appendix. The last three columns report the monthly and annual empirical values of each moment in the data and the monthly values obtained in the simulation. Panel A reports the target moments for real variable parameters: the UIP slope coefficient $\beta_{U I P}$; the mean, standard deviation, and autocorrelation of the U.S. real short-term interest rate $r^{u s}$; the average standard deviation of the changes in the real exchange rate $\Delta q$; the standard deviation of the log of the real SDF $\tilde{m}$; and the average return $\tilde{r x}$, adjusted for the Jensen term, of a U.S. investor on currency markets, as well the Feller coefficient. Panel B reports the target moments for inflation parameters: mean inflation for the United States and mean and standard deviation of the inflation for the average emerging market $(\mathrm{em})$, along with the average $R^{2}$ in regressions of each country for the average emerging market $(\mathrm{em})$, along with the average $R^{2}$ in regressions of each country's fid ation on world inflation, and the average term premium. Panel $C$ reports the target moment for the recovery process parameters and the $L M H$ default premiums. Panel D reports the target that $\operatorname{var}\left(z^{i}\right)=\left(\sigma^{2} \theta\right) /\left(1-\phi^{2}\right)$ and $\operatorname{var}\left(z^{w}\right)=\left(\left(\sigma^{w}\right)^{2} \theta^{w}\right) /\left(1-\left(\phi^{w}\right)^{2}\right)$. Panel E reports untargeted moments and corresponding values in the simulation. For means and standard deviations, we report annualized values by multiplying their monthly counterparts by 12 and $\sqrt{12}$. The othe moments are not annualized. The target values in panels $\mathrm{A}$ and $\mathrm{D}$ are based on our sample inflation targets are based on monthly CPI data from Datastream; and recovery targets are based on historical default probabilities discussed in Section B. 
Global Risk in Long-Term Sovereign Debt

Table 5

Parameter values

A. SDF parameter

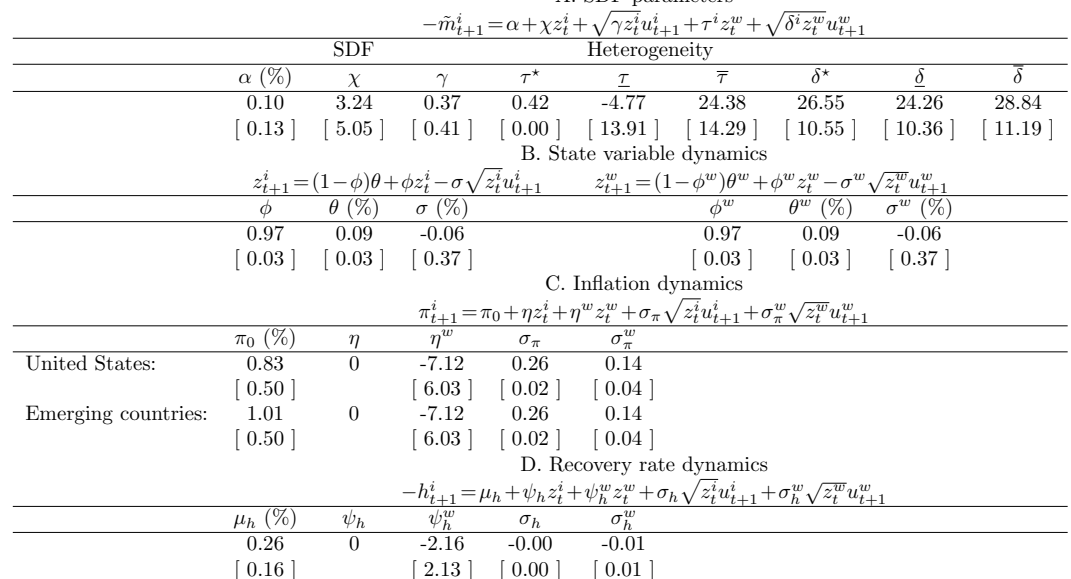

This table reports the main parameter values used in the simulation for the U.S. and emerging markets. Panel A reports the parameters of the SDFs, and panel B of the state variable dynamics. All countries share the same parameter values, except for the loadings on the global shock, $\delta^{i}$, and on the global state, $\tau^{i}$. The values of $\delta^{\star}$ and $\tau^{\star}$ correspond to the U.S. and to the average emerging market. Panel $\mathrm{C}$ reports the parameter values of the inflation process for the U.S. and the average emerging market. Panel D reports the parameter values for the recovery rate process for risky bonds. All parameters are estimated jointly using a version of the generalized method of moments (GMM) estimator. Refer to Table 4 for the target moments and corresponding simulated moments. Refer to Section H.V in the Internet Appendix for details on the parameter restrictions imposed in the estimation. 


$$
\text { "em port"final" — 2021/5/3 — 12:15 — page } 44 \text { — \#44 }
$$

Review of Asset Pricing Studies / v 00 n 02015

Table 6

Bond portfolios (simulated data)

\begin{tabular}{|c|c|c|c|c|c|c|}
\hline Portfolio & 1 & 2 & 3 & 4 & 5 & $1-5$ \\
\hline & \multicolumn{6}{|c|}{ Exposure to global shock: $\delta^{j}$} \\
\hline Mean & 22.46 & 21.93 & 21.21 & 20.94 & 20.41 & 2.05 \\
\hline \multirow[t]{2}{*}{$S E$} & {$[0.46]$} & {$[0.25]$} & {$[0.10]$} & {$[0.20]$} & {$[0.44]$} & $0.89]$ \\
\hline & \multicolumn{6}{|c|}{ Loading global state: $\tau^{j}$} \\
\hline Mean & -5.56 & 0.91 & 9.63 & 13.00 & 19.47 & -25.03 \\
\hline \multirow[t]{2}{*}{$S E$} & {$[5.74]$} & {$[3.00]$} & {$[1.23$ ] } & {$[2.40$ ] } & [ 5.08 ] & {$[0.89]$} \\
\hline & \multicolumn{6}{|c|}{ Forward discount: $f_{t}-s_{t}$} \\
\hline Mean & -13.70 & -5.48 & 2.35 & 9.83 & 18.78 & -32.48 \\
\hline \multirow[t]{2}{*}{$S E$} & {$[0.00]$} & {$[0.00]$} & {$[0.00]$} & {$[0.00]$} & {$[0.00]$} & {$[0.01]$} \\
\hline & \multicolumn{6}{|c|}{ Exchange exchange rate growth: $\Delta s_{t+1}$} \\
\hline Mean & -14.49 & -6.48 & 4.28 & 8.43 & 16.71 & -31.20 \\
\hline \multirow[t]{2}{*}{$S E$} & {$[0.01]$} & {$[0.01]$} & {$[0.01]$} & {$[0.01]$} & {$[0.01]$} & {$[0.01]$} \\
\hline & \multicolumn{6}{|c|}{ Term premium: $r_{t+1}^{(60), *, f}-r_{t+1}^{(1), *, f}$} \\
\hline Mean & 3.38 & 2.00 & 0.56 & -0.84 & -2.52 & 5.90 \\
\hline \multirow[t]{2}{*}{$S E$} & {$[0.01]$} & {$[0.01]$} & {$[0.00]$} & {$[0.00]$} & {$[0.01]$} & {$[0.02]$} \\
\hline & \multicolumn{6}{|c|}{ Default premium: $r_{t+1}^{(60), *}-r_{t+1}^{(60), *, f}$} \\
\hline Mean & 0.68 & 0.71 & 0.74 & 0.77 & 0.80 & -0.12 \\
\hline \multirow[t]{2}{*}{$S E$} & {$[0.00]$} & {$[0.00]$} & {$[0.00]$} & {$[0.00]$} & {$[0.00]$} & $0.00]$ \\
\hline & \multicolumn{6}{|c|}{ Bond dollar excess returns: $r x_{t+1}^{(60), \$}$} \\
\hline Mean & 4.84 & 3.71 & -0.63 & 1.33 & 0.35 & 4.50 \\
\hline \multirow[t]{2}{*}{$S E$} & [ 0.02$]$ & [ 0.02$]$ & {$[0.01]$} & {$[0.01]$} & {$[0.01]$} & 0.02 \\
\hline & \multicolumn{6}{|c|}{$\mathrm{SDF}: m_{t+1}$} \\
\hline Var & -0.03 & -0.00 & 0.03 & 0.05 & 0.07 & 0.11 \\
\hline \multirow[t]{2}{*}{$S E$} & {$[0.01]$} & {$[0.01]$} & [ 0.01$]$ & {$[0.01]$} & [ 0.01$]$ & 0.01 \\
\hline & \multicolumn{6}{|c|}{ Permanent component SDF: $m_{t+1}^{\mathbb{P}}$} \\
\hline $\operatorname{Var}$ & 0.26 & 0.15 & 0.04 & -0.09 & -0.24 & -0.50 \\
\hline \multirow[t]{2}{*}{$S E$} & [ 0.01 ] & [ 0.01 ] & [ 0.01$]$ & {$[0.01]$} & [ 0.01$]$ & 0.01 \\
\hline & \multicolumn{6}{|c|}{ Temporary component SDF: $m_{t+1}^{\mathbb{T}}$} \\
\hline $\operatorname{Var}$ & -0.05 & -0.01 & 0.00 & -0.00 & -0.02 & 0.03 \\
\hline$S E$ & {$[0.00$ ] } & {$[0.00]$} & $0.00]$ & {$[0.00]$} & {$[0.00]$} & {$[0.00]$} \\
\hline $\begin{array}{l}\text { the global st } \\
\text { fault premiur } \\
\text { onths. The las } \\
\text { d temporary } \\
\text { vestors (i.e., } \\
\text { untries by the } \\
\text { bootstrap. } \\
\text { nulated data, } \\
\text { e shocks and } \\
\text { eir exposure } \\
\text { cond, we use } \\
\text { tturities. }\end{array}$ & $\begin{array}{l}\left(\tau^{i}\right) ; \text { the } \\
\text { and the bc } \\
\text { three panel } \\
\left.{ }^{\mathbb{T}}\right) \text { compon } \\
\text { 2) var }\left(m_{t+}\right. \\
\text { hort-term i } \\
\text { bond retu } \\
\text { arameter va } \\
\text { nerate simu } \\
\text { the global }\end{array}$ & $\begin{array}{l}\text { ward discc } \\
\text { lexcess re } \\
\text { eport, for } \\
\text { ts, the mea } \\
\text { - (1/2)var } \\
\text { rest rates. } \\
\text { moments } \\
\text { es are repc } \\
\text { ed data fo } \\
\text { ck } \delta^{i} \text { and }\end{array}$ & $\begin{array}{l}\text { ts; the exc } \\
\text { ns in doll } \\
\text { average p } \\
\text { difference } \\
j \\
t+1 \text {, for } \\
\text { estandarc } \\
\text { annualize } \\
\text { d in Table }\end{array}$ & $\begin{array}{l}\text { ng on the } \\
\text { nge rate g } \\
\text { Bonds a } \\
\text { folio SDF } \\
\text { the half-va } \\
1, \ldots, 4) \text {. } \\
\text { rrors, repo } \\
\text { and repor } \\
\text { First, we }\end{array}$ & $\begin{array}{l}\text { th; the ter } \\
\text { for the mat } \\
\text { ), and its } \\
\text { nce with re } \\
\text { form portf } \\
\text { d in bracke } \\
\text { in percent } \\
\text { aw } 100,000 \\
\text { differ only } \\
{ }^{i} \text { ), and th }\end{array}$ & $\begin{array}{l}1 \text { and short in } \\
\text { ); the loading } \\
\text { premium; the } \\
\text { rity of } m=60 \\
\text { rmanent }\left(m^{\mathbb{P}}\right) \\
\text { pect to foreign } \\
\text { ios by sorting } \\
\text {, are obtained } \\
\text { bs points. For } \\
\text { ith respect of to } \\
\text { United States. } \\
\text { with different }\end{array}$ \\
\hline
\end{tabular}

